\title{
Paediatric Physical Facilities Design Characteristics in Southwestern Nigerian University Teaching Hospital: Lesson from Netherland Children Hospital
}

\author{
Muyiwa Lawrence Akinluyi ${ }^{1, *}$, Folusho Charles Awe ${ }^{2}$, Oluwatoyin Olugbenga Adeleye ${ }^{1}$, \\ Mayowa Paul Ogunruku' \\ ${ }^{1}$ Department of Architecture, Joseph Ayo Babalola University (JABU), Nigeria \\ ${ }^{2}$ Department of Physical Planning, Ekiti State University, Nigeria
}

Received December 2, 2018; Revised March 21, 2019; Accepted March 28, 2019

Copyright $(2019$ by authors, all rights reserved. Authors agree that this article remains permanently open access under the terms of the Creative Commons Attribution License 4.0 International License

\begin{abstract}
This study appraised the influence of design characteristics of the paediatric hospital physical facilities with a view to develop the physical facilities design characteristics policies for paediatric hospital designers, managers and policy makers. In this study, the hospital physical facilities are defined by the spaces used by the professional staff, equipment, the building form, their furniture and fixtures. Also, the design characteristics of the hospital physical facilities are defined by the building proximity, privacy, wayfindings, flexibility and adaptability. The notable paediatric hospital selected in the developed country is Emma Kinderziekenhuis Pediatric Hospital in Amsterdam, Netherland because it has developed a remarkable work in the healthcare settings with a deep concern on child-centred design, which were informed, implemented and accompanied by architects. Also, Peadiatric department of University College Hospital (UCH), Ibadan Nigeria was selected because it is the largest city in Nigeria which can be used to generalize what is obtained in peadiatric hospital physical facilities in southwestern Nigeria. Through analysis of one of the notable hospitals in both the developed and developing worlds, the design characteristics of selected hospital were examined using case study method such as the use of building plans, the site layout and the use of photograph among others. The results of the investigation show that hospital design characteristics have a great influence on both the patients and staff including the visitors. However, the planning and design characteristics of the physical facilities in the Netherland Children Hospital were found to be very good compared with its counterpart in Southwestern Nigerian University Teaching Hospital. It is, however, concluded that, the Nigerian University Teaching Hospitals should learn from the design characteristics appraised from the Netherland Children Hospital. The
\end{abstract}

result of this study will be useful as a design policies standard for the Nigerian government, healthcare developers and children hospital designers in southwestern, Nigeria.

Keywords Appraisal, Healthcare, Physical Facilities, Design Characteristics, Southwestern, Nigeria

\section{Introduction}

Healthcare practice has expanded over the past 24 years and incorporation of design and satisfaction research in the hospital environment has not been popular among the researchers in Africa (Shepley \& Song, 2014). Many studies and researches are now underway to more completely understand what patients and staff truly need in appraising the hospital physical facilities. Hospital environment as a place where patients seek medical treatment and staff provides continuous support, creating healing environment with appropriate physical facilities need to be appraised (Hussain \& Ghith, 2014). Apart from being a large consumer of natural resources, it also has strong influence on the economy of any nation (Guenther $\&$ Vittori, 2008). Constructing a hospital may, therefore, be referred as building a 'city within a city' where a hospital is seen as a city with its own interior complexity, while it does not cease to be a constituent element of the city. Independently of being a general or a specialized hospital or even a clinic, it will relate with the city in terms of location, scale and accessibility, affecting people's lives. It is part of the architect role trying to bridge the gap between medical world and everyday life.

Therefore appraisal is important for improving the 
healthcare physical facilities which in turn could improve patient health and staff performance. The physical facilities of a hospital include the building, amenities, adequate equipment for patient care, patient records and laboratory (Ogaji, Giles, Daker-White \& Bower, 2015). The hospital facilities, however, requires effective support of critical infrastructure such as a well-designed space for operating theatres, lobbies, entrance hall, waiting area, consulting rooms, conveniences, in-patient wards, out-patient corridors and medical treatment for the patients offered by the trained professionals' staff (Oladejo Umeh \& Ogbuefi, 2015).

Hospital physical facilities generally consists of both the in-patient, out-patient and attached facilities and amenities. The in- patient facilities provide overnight stay for patient medical care such as paediatric ward, observation ward among others while the out-patient facilities provide premises for consultation such as drop off, registration counter, waiting area, consultation room, pharmacy and toilet facilities (Samah, Ibrahim \& Wahab 2013). The hospital physical facilities may be modified through change or redesign, for example, existing physical structures or spaces within the hospital environment may be restructured or improved upon such as additional space provided in waiting areas and patient-care rooms among others (Quan, Joseph, Keller, \&Taylor, 2011).

Paediatrics, as the name predicts, focus on children's diseases, clarifying the distinction between them and adults. Children's diseases occur in different ways and also respond differently to medications due to their particular pathophysiology. There are many authors that followed the typological evolution of hospitals, though the specific evolution of paediatric hospitals is lesser known. Nevertheless, a new typology usually emerges in unsettled times of acute need. Paediatric Hospital environments need to be constructed for child friendly and children's right to dignity, privacy, family support and self-control (Lambert, Coad, Hicks, Glacken, 2013) Further literature revealed that, hospitals that care for infants and children must provide inpatient areas that are safe, furnished appropriately, equipped properly, staffed adequately, radiology and laboratory services. The facility design for children must contain single- or double-occupancy rooms large enough to accommodate parents, who may choose to stay with their children, location of beds to allow for observation and supervision of patients by nursing staff, covered electrical outlets, appropriate window locks and door latches, padding of all sharp edges, and nonslip, easily maintained floor coverings, air, oxygen, suction equipment, and electrical outlets at each bed, with access to the hospital emergency power system, age-appropriate furniture, cribs equipped with safe overhead restraints and beds with covers on mechanical or electrical controls, area set aside for play, entertainment, education, and other child life activities and Treatment room and procedures (Schaeffer, 1998). Thus, experts and researchers are needed to develop strategies for renovation and reconstruction of new building and environmental facilities to address the current growth in Nigeria. This study focused the psychological design issues of the physical facilities relating to factors such as proximity and wayfinding flexibility and adaptability of different types of spaces provided.

\section{Relevant Literature Review}

\subsection{Hospital Buildings and Evolution of Paediatric Hospital}

Hussain \& Ghith, (2014) defined hospital buildings as an institution where the sick or injured are given medical or surgical care. Hospital is a health care institution providing patient treatment with specialized staff and equipment. Hospital buildings are a building where patients seek medical treatment and staff provides continuous support, creating healing environment with appropriate physical aspects. The world health organization define hospital as an healthcare institutions that have an organized medical and other professional staff, and inpatient facilities, and deliver medical, nursing and related services 24 hours per day, 7 days per week. Hospitals offer a varying range of acute, convalescent and terminal care using diagnostic and curative services in response to acute and chronic conditions arising from diseases as well as injuries and genetic anomalies. In doing so, they generated essential information for research, education and management. Traditionally oriented on individual care, hospitals are increasingly forging closer links with other parts of the health sector and communities in an effort to optimize the use of resources for the promotion and protection of individual and collective health status (Hussain \& Ghith, 2014).

From History, Verderber \& Fine (2000) identified six periods through which hospital design has evolved. These include the Ancient era, the Medieval period, the Renaissance, the Nightingale era, the Minimalist Mega hospital and the Virtual Health scope. The authors, however, affirmed that, among the first four periods, the Nightingale era is most relevant in terms of room layout and occupancy. However, the first prominent Islamic hospital was founded in Damascus, Syria in around 707 with assistance from Christians and majority of people agreed that the establishment at Baghdad was the most influential; it opened during the Abbasid Caliphate of Harun al-Rashid in the 8th century. St Thomas Hospital in London, which opened in 1871, was the first hospital that used her guidelines in the planning of its wards (Verderber \& Fine, 2000; Hussain \& Ghith, 2014). According to history, people from the upper income groups wanted privacy during their healing process, so they created a demand for single-occupancy rooms. Gradually, private 
and semi-rooms replaced multi-bed large wards in hospitals and, by the mid-twentieth century, the Nightingale ward was a dying template (Miller et. al.1995).

Historically, healthcare architecture has combined an idea of a supporting environment with new techniques. In the earlier history of hospitals there was an awareness of good architecture and access to nature as important parts of constituting a healing environment for the sick. The emerging major hospitals in the late 1800s and early 1900s where technically very advanced. However, in the $1950 \mathrm{~s}$ and 1960s, many hospitals still favored open smaller wards over private rooms because of the staff efficiency issue. Even in the early 1970s, advocates of multi-occupancy rooms were stating that patient privacy (in single occupancy rooms) meant a sacrifice of continuous supervision. They attributed the trend towards single rooms in hospitals to the general movement towards privacy in all aspects of 20th century life (Thompson \& Golden, 1975). All-private-room argument was waged mainly as a reflection of societal progress rather than on the basis of strictly rationalized medical justification (Verderber \& Fine, 2000).

From the pediatric perspective, Dutch Paediatric Hospitals, which appeared in Rotterdam, in a scenario of sickness and premature death in the mid- $19^{\text {th }}$ century Rotterdam was the big stage of Industrial Revolution in the Netherlands and the new centre of world economy, because of the construction of the new port (Tellier 2009; Pinhão, 2016). For this reason, there was a massive migration from the countryside to the city, increasing poverty, unemployment, poor hygienic conditions and housing problems. Based on these circumstances, there was a call for government intervention in 1850 to prevent diseases spread and improves life quality. However, children were not included in the plans, since they were not part of the working group. Sick children were nursed at home and treated by general practitioners (Offringa 2003; Pinhão, 2016). In 1863, an epidemic of measles, smallpox and whooping cough contributed to a tremendous increase of infant mortality, with $59 \%$ of children dying younger than 5 years (Lieburg 2004). Also, general hospitals were not prepared to take care of sick children, placing children and adults, with all kinds of infectious diseases, in the same room. A new awareness on sick children started in Paris (1802), Vienna (1837), London (1852) and spread all over the world. This progress was also felt in the Netherlands, with the establishment of the first paediatric hospital that appeared in Rotterdam, in 1863. Different from the corridor type and other current tendencies, the first paediatric hospitals were forced to occupy residential houses due to economic problems. After Rotterdam, many other children's hospitals opened in other cities, such as Amsterdam (1865), Arnhem (1881), The Hague (1885), Utrecht (1888), Dordrecht (1891) and Groningen (1892). It is curious that the individuals who took the initiative were mainly doctors, which show that they were the ones who could closely identify the problem. During the early days of paediatrics, they were purely charitable institutions, living from the money collected between the privileged classes and were specially aimed to treat poor children from families in need. Moreover, they frequently adopted the name of the regent Queen in order to be more likely to get support. Only in 1892, the Dutch Society of Paediatrics was founded, including the medical directors of all children's hospitals, and the paediatric medical specialization was introduced (Offringa 2003).

In this modern day, Hospitals are considered as the integral part of healthcare industry including health as whole (Public Health), Pharmaceuticals and other associated fields. Making patient and employee friendly hospitals setup and environment are the big challenges nowadays. Quality interventions have given a new insight and scope for improvements, not only the services of the hospitals but also to make great structure (Hussain \& Ghith, 2014). Few accreditation agencies in the field of Hospital accreditation are working day and night to help healthcare providers directly to improve the hospital services qualities and make a healthy and safe environment hospital-wide and set a benchmark for other hospitals. (Hussain \& Ghith, 2014). Healthcare buildings play a significant role in delivering healthcare services and outcomes. The global tendency to involve stakeholders in the design process of healthcare buildings has added more complexity to the design process of hospitals (Alalouch, Aspinall \& Smith, 2016).

There is scientific evidence that the physical setting in which medical care is provided can play a considerable role in patients' health and well-being (Ulrich \& Zimring, 2004). However, it is a big challenge to the architect to perfectly integrate the architectural design and the natural environment which in turn produced the design of the physical environment of the hospital. Some authors stress the need for a more exhaustive review of the benefits of physical settings on health care, a review that should be based on a consensus of the taxonomy of the relevant physical dimensions (Berg, 2005). The recent research-based initiatives such as Evidence-Based Design (Ulrich, 2000; Ulrich, Quan, Zimring, Joseph, and Choudhary, (2003) and the global tendency to involve stakeholders in the design process of healthcare buildings has added more complexity to the design process of hospitals (Alalouch, Aspinall \& Smith, 2016).

\subsection{The Design of the Hospital Physical Facilities}

Design facility layout refers to the arrangement of different types of spaces, equipment, machineries and furnishing facilities within a building envelop after considering the various objectives of the facility (Tompkins el al. 1996). Its main objective is to design effective workflow as to make space, equipment and workers more productive. An effective facility design 
layout ensures that there is a smooth and steady flow of production material, equipment and manpower (Teicholz, 2001). Facility design layout looked at the physical allocation of space for economic activity in an organization which includes available space, user's safety, final product and convenience of operations (Tompkins el al. 1996). Design facility when properly carried out should be able to provide an ideal relationship between the building, raw materials, equipment and manpower under safe and comfortable environment which its principles depend on the flexibility for expansion or modification and optimum space utilization. From health care perspective, the basic meaning of healthcare design facility refers to the space in which health care activities take place. The layout and design of that space impact greatly how the work is done. The key to good facility layout and design is the integration of the needs of patients, materials and equipment in such a way that they create a single, well-functioning system (Becker \& Parsons, 2007). Hospital design facility is important, because it provides a unique opportunity to use current and emerging evidence to improve the physical facilities of the hospital environment (Reiling; Hughes \& Murphy, 2003). It is also an important component of healthcare overall operations, both in terms of maximizing the effectiveness of healthcare delivery process and meeting the needs of hospital users (Tompkins el al. 1996).

However, many studies on health care have been carried out on the actual architectural design of a hospital facility and its effect on patient health and staff performance. Few of these studies have considered the influence of facility design empirically on patient health and staff performance. For example; Becker \& Parsons, (2007) emphasized that the quality of care issues are central to the fundamental business enterprise of a hospital, and have been linked to many different facets of facility design such as poor functioning space, poorly functioning ventilation systems, crowded and noisy medication rooms, flooring materials that contribute to falls, design and layout of nursing units (Marberry, 2006; Becker \& Parsons, 2007). The authors advocated and stressed the fact that hospital facility design should be provided with adequate space, equipment and qualified personnel and should be suitable for execution of activities, spacious enough and cause no contamination to the environment. Also, the study conducted by Henriksen et al, (2007) identified design elements which are critical in ensuring patient well-being and staff performance such as patient-centeredness, safety, effectiveness, efficiency, timeliness and equity.

According to Reiling; Hughes \& Murphy, (2003) stated that, design of a structure with its fixed and moveable components can have a significant impact on human performance, especially on the health and safety of employees, patients, and families. The design factors that can influence the degree of attractiveness of a facility include not only the design of the production area itself, but the impact of the facilities on the users. The recent study conducted by Becker and Jones-Douglas, (2006) illustrates how research can help facility professionals, architects, and hospital administrators make more informed facility decisions. Healthcare industries have turned to evidence-based design as a means of making more informed decisions about hospital facility designs that can help improve patient safety, and generate high levels of patient satisfaction. Facility design has been shown, through systematic research, to have such a significant effect on outcomes considered essential to the long-term survival and performance of the organization (Becker \& Parsons, 2007). Further review of the literature was done to identify the paediatric hospital design characteristics. These were discussed below.

\subsection{The Paediatric Healthcare Design Characteristics}

This study appraised the hospital physical facility design in terms of the psychological design characteristics such as privacy, proximity and wayfingdings, flexibility and adaptability. The reviews of these issues are explained below;

\subsubsection{Privacy within the Physical Facilities}

Privacy is a complex concept that is not easy to define (Solove, 2006). It is a multi-faceted construct which could be interpreted differently by different people. Sundstrom et al. (1980) refers to the architectural privacy as a visual and acoustic isolation supplied by an environment. Privacy is other factor closely related with control, being defined as 'an interpersonal boundary process in which a person or group regulates interaction with others' (Altman, 1975). This ability to control interactions can be considered even more important than the proper social interaction (Shepley 2005) since it enables the controlled access to personal space or to the groups whom one belongs. However, both privacy and socialization are important factors and should be balanced in an effective way to offer a better hospital environment (Pinhão, 2016).

The focus here is on visual privacy as a function of the spatial arrangements of spaces. Patients' privacy in hospital settings is widely recognized as important factors for patients' well-being and satisfaction. Fischl, (2004) define privacy preference as the biased interpersonal boundary by which people regulate interaction with others (Fischl, 2004). On psychological view, the importance of privacy for system-maintenance and system-development has been acknowledged by both theory and research (Newell, 1998). Fulfilling people's needs for privacy is linked to their well-being the evolution of recent trends (Mead \& Bower, 2002; Berg, 2005) have further emphasized the concept of patients' privacy and its importance for patients' well-being. However, a survey by Jones and Bullard (1993) of 140,000 hospital patients showed privacy to be of primary concern to patients. Healthcare providers have a duty to treat patients with 
respect to protect their personal data. Single-sex accommodation being with other patients of the same gender is an important component of privacy and dignity. This type of accommodation can take a number of different forms, for instance, the single-sex wards, single-sex bedded bays and single rooms.

The fact is that routine care protocols and nursing procedures sometimes violate patient's personal space, invading a level that was only supposed to be reached by family members and closer friends (Hamilton 2009; Pinhão, 2016). Furthermore, privacy is also neglected when patients sleep in shared rooms with strangers; financial information is published; the triage is done in public spaces; patients are left on gurneys in corridors (Shepley 1998); or simply the inexistence of a space to be alone or to talk with someone in particular. Several studies have been considering ways to provide 'spaces to be alone'. Children, in particular, identify a strong correlation between privacy and the type of room attributed, considering that single rooms provide a greatest degree of control (Lambert et al. 2014; Pinhão, 2016)).The hospital should provide a combination of these different types of accommodation. In addition to the segregation based on gender, the patients prefer to have the ability to make their personal space private when necessary. Empirical study was conducted by LaVela, Etingen, Hill \& Miskevics, (2015) to measure patients' perceptions of the physical environment, in which healthcare was delivered. The authors find out that overcrowding, and privacy for conversation determines the environmental physical quality of a healthcare environment. Similarly, a study conducted in a maternity health centre from Malawi found that, despite being treated politely, lack of auditory and visual privacy led women to not using a maternity facility. Hence provisions to ensure privacy in health facilities are warranted (Lule, Tugumisirize \& Ndekha, 2000).

\subsubsection{Proximity within the Physical Facilities}

The study of proximity in hospital physical facilities seems to be a very scarce area of study. The proximity of patients and staff is considered as the absolute traveling distance to their nearest hospital and the distance travelled between the hospitals physical facilities (Khan, 2012). Studies have showed that visiting rates are strongly correlated with travelling distance from the hospital and utilization of inpatient and outpatient hospital care areas. Steinke, (2015) regarded proximity as an important concept that determines the attributes of the physical setting of a healthcare layout environment. Similarly, Pitt, Chotipanich, Issarasak, Mulholland and Panupattanapong (2014) conducted a relationship between hospital services, physical facilities and level of satisfaction with services and facilities shows there was significant relationship between the treatment rooms and lobby areas, which supports the argument that it is important for patients to have the two areas in close proximity.
From paediatics view, the study of Lambert, Coad, Hicks, Glacken, (2013) pointed out young children's need to experience proximity environment. Some children felt they could choose what they wanted to do at their bedside and wanted the playroom or schoolroom to be located very close to their room. Khan, (2012) assumed that operational efficiency may be achieved through reducing travel distance \& time to serve patient, increasing accessibility to service, facilities and geographical proximity to patient, increasing inter department movement and patient satisfaction.

\subsubsection{Wayfindings within the Physical Facilities}

The problems in wayfinding for patients and visitors are common in hospitals. These difficulties can result in feelings of agitation, disorientation and a loss of control (Devlin, 2003). Way finding may help reduce travel time, waiting time, service delivery time and increasing patient satisfaction, thereby improving operational efficiency in healthcare settings (Khan, 2012).Way finding constitutes one of the aspects that influence the sense of control. It is considered a 'spatial problem solving', and extensively defined as 'the process of reaching a destination, whether in a familiar or unfamiliar environment' (Arthur and Passini 1992; Pinhão, 2016). A mental image of the place layout is required for a spatial orientation. Understanding the actual location, the destination location, the route to choose, how to follow that route or when the destination is reached, is part of the problem-solving process (Huelat 2007).The elderly, visually impaired, and people of non-English speaking background are at higher risk of losing their way. Although colour coding is often used to assist in wayfinding, one group of authors warns that it is often misunderstood by patients and visitors to the hospital (Dalke, Little et al. 2006). Physical design is also important in assisting internal way finding by ensuring that interdependent services/departments are co-located, and by reducing movement around the site (NHS\& NHSGG Report, 2006; Khan, 2012). In healthcare field, the early work of Carpman (1986) defends that way finding affects stress and can be improved through nomenclature, density (number of signs), context, placement, and visibility. A poor way finding in such typology can lead patients to be late to medical appointments or get lost easily, which represents an avoidable environmental stressor. Therefore, architects play an important role not only in the image and placement of signs, but also in the way spaces are designed. Patient's position within the building can be clarified, for example by placing windows in corridors, designing clear pathways, enabling easy-to-see elevators, creating strategic placed landmarks and designing an easily identifiable entrance (Huelat 2007).

Zwart and Voordt, (2015) explored the impact of these architectural hospital design factors on patient satisfaction in a psychiatric facilities. The findings showed that design assessment regarding wayfinding is a valuable input to 
support evidence-based design in the hospital environment. Steinke, (2015) found out that wayfinding is an important concept that determines the attributes of the physical setting of a healthcare layout environment. Parke, (2007) pointed out that wayfindings is a crucial physical design elements of an elder friendly hospital. Further studies by Samah, Ibrahim \& Wahab (2013) showed that wayfinding is an interior physical design component of an outpatient healthcare facilities. Similarly, Alvaro, wilkinson, Gallant, Kostovski \& Gardner, (2015) included way finding as hospital design factor in an attempt to assess the impact of architectural design on psychosocial well-being among patients and staff in the context of a new complex continuing care and rehabilitation facility. Kline, Baylis, Chatur, Morrison, White, Flin, Ghali, (2007) considered wayfindings around the hospital as a factor that enhanced the physical facilities of the patient care environment which also improved patients' overall satisfaction.

\subsubsection{Adaptability and Flexibility of the Physical Facilities}

Flexibility referred to ability to expand or remodel easily or adaptable (John, Ronda, Mike \& Murphy, 2001). The ability to adapt space for different or evolving services in health care facility refers to the concept of adaptability. Hendrich et al. (2009) investigated the impact of an evidence-based design of 56 new acuity-adaptable rooms for a combined coronary critical care and step-down unit (Hendrich et al. 2009). The researchers found that two different levels of acute care (intensive and step down cares) could effectively be merged together into a single patient room by making the room acuity adaptable to accommodate the changing needs of patient. Steinke, (2015) saw adaptability is an important factor that determines the attributes of the physical setting of a healthcare environment. Many design and construction concepts for adaptability and flexibility can be applied in a room that is higher than normal ceilings to allow changes to be incorporated in the future. Similarly, space around the bed is sized so that procedures could be performed in the room in the future. These could create flexibility and adaptability in the health care facilities. Personalization is an appreciated aspect of hospitals' capacity of adaptability and flexibility (Pinhão, 2016), even though there is scarce literature about this theme in paediatric hospitals, it can be highlighted the work of Blumberg and Devlin (2006), in which they stated that being able to bring personal belongings from home and to personalise the bed area, was important for teenage group. This way, they have the possibility to establish their identity and appropriate level of comfort (Pinhão, 2016).

\section{Methodological Approach to This Study}

Through case study method of data collection, one notable hospital was selected in the developed world for design appraisal based on design parameters. Appraisal was done through personal observation and documentation such as documentation of building plans, the site layout, base map, site location and the use of photograph among others. For the purposes of this study, paediatric hospital buildings were appraised using the selected design criteria such as privacy, wayfinding, flexibility, adaptability and proximity of the physical facilities. The notable paediatric hospital appraised in the developed country like Netherlands is Emma Kinderziekenhuis Pediatric Hospital in Amsterdam, Netherland. This hospital have developed a remarkable work in the healthcare settings with a deep concern on child-centred design, which were informed, implemented and accompanied by architects, were taken into account. The appraisal of this hospital was done to serve as a lesson for the developing country like Peadiatric department of University College Hospital (UCH), Ibadan Nigeria. Peadiatric Healthcare facilities in UCH, Ibadan was selected because is the largest city in Nigeria which can be used to generalize what is obtained in peadiatric hospital physical facilities in southwestern Nigeria. The selected pediatric hospitals were appraised below;

\section{The Developed World Hospital: Emma Kinderziekenhuis Pediatric Hospital in Amsterdam, Netherland}

\subsection{The History of Amsterdam, Netherland and Its Architecture}

Amsterdam is the largest city and the national capital of the Netherlands. The city is located in the south of the province Noord (North) Holland at the mouth of the Amstel River. The city was the European Capital of Culture in 1987. In 2014, Amsterdam had a city population of about 814,000 inhabitants, approximately 2.3 million people live in its Metropolitan region. Official language is Dutch, English is widley spoken. Amsterdam is Located in Rotterdam which is the major port of the Netherlands. Amsterdam became one of the most important ports in the world during the Dutch Golden Age (17th century), as a result of its innovative developments in trade. During that time, the city was the leading centre for finance and trade. In the 19th and 20th centuries the city expanded, and many new neighbourhoods and suburbs were planned and built. Since the annexation of the municipality of Sloten in 1921 by the municipality of Amsterdam, the oldest historic part of the city lies in Sloten, dating to the 9th century. As the commercial capital of the Netherlands and one of the top financial centres in Europe, Amsterdam is considered an alpha- world city by the Globalization and World Cities (GaWC) study group. The city is also the cultural capital of the Netherlands. Many of the world's largest companies are based in Amsterdam or established their European 
headquarters in the city, such as leading technology companies Uber, Netflix and Tesla. In 2012, Amsterdam was ranked the second best city to live in by the Economist
Intelligence Unit (EIU). The Port of Amsterdam to this day remains the second in the country, and the fifth largest seaport in Europe. See as represented figure 1 and 2.

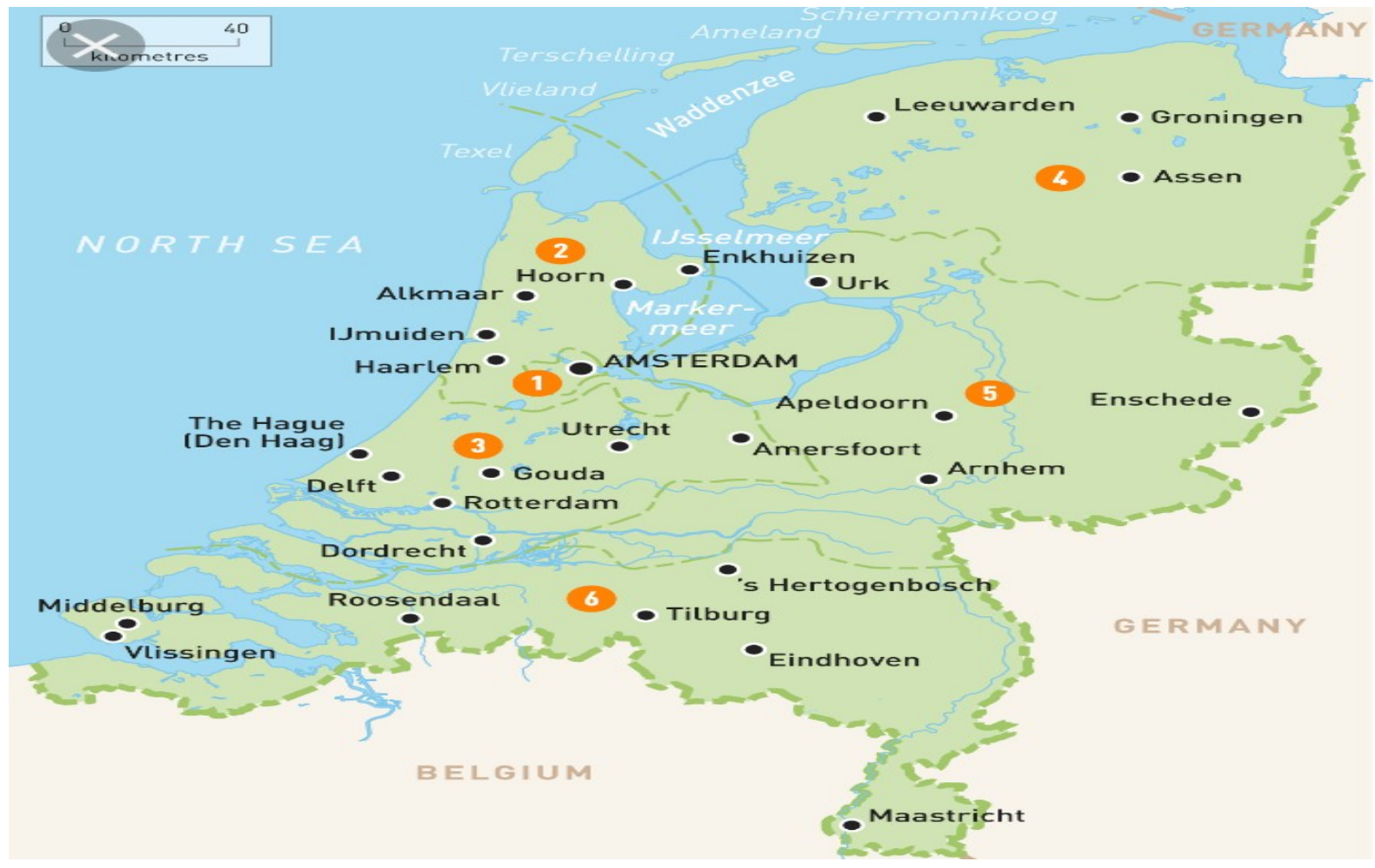

Figure 1. Showing the Location of Amsterdam in Netherlands

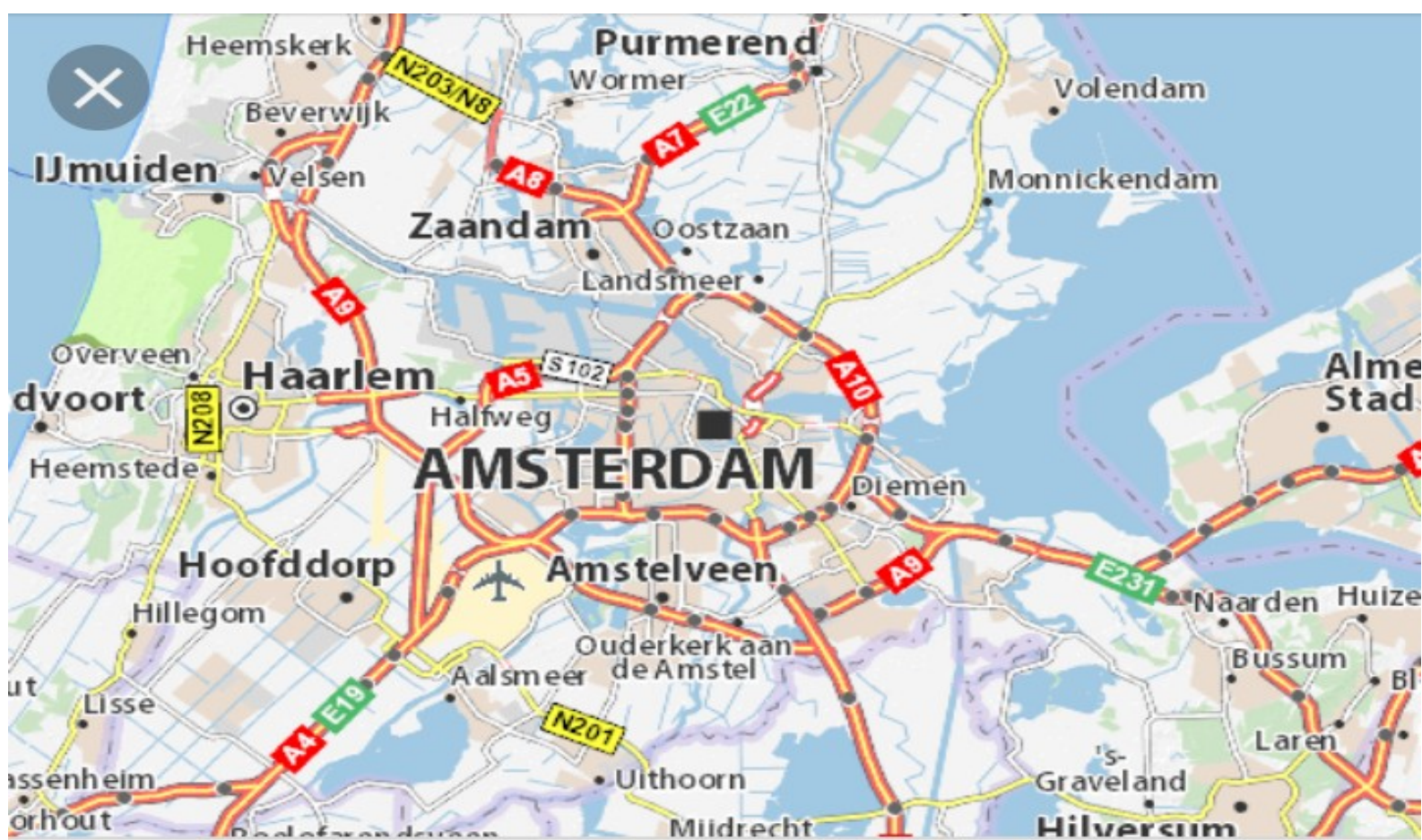


The Architecture of Amsterdam; The Scheepvaarthuis, by architects Johan van der Mey, Michel de Klerk, Piet Kramer is characteristic of the architecture of the Amsterdam School. The oldest building in Amsterdam is the Oude Kerk (English: Old Church), at the heart of the Wallen, consecrated in 1306. The oldest wooden building is Het Houten Huys at the Begijnhof It is also an example of Gothic architecture in Amsterdam. The oldest stone building of the Netherlands, The Moriaan is built in 's-Hertogenbosch. Amsterdam quickly developed its own Renaissance architecture. These buildings were built according to the principles of the architect Hendrick de Keyser. One of the most striking buildings designed by Hendrick de Keyer is the Westerkerk. In the 17th century baroque architecture became very popular, as it was elsewhere in Europe. The leading architects of this style in Amsterdam were Jacob van Campen, Philips Vingboons and Daniel Stalpaert, Begijnhof is one of the oldest hofjes in Amsterdam. The housing market is heavily regulated. In Amsterdam, 55\% of existing housing and $30 \%$ of new housing is owned by Housing Associations, which are Government sponsored entities.

However, the major healthcare facilities identified in Amsterdam include Emma Children's Hospital is part of the Academic Medical Centre (AMC), which is affiliated with the University of Amsterdam and considered the largest hospital in the city. The AMC is located in the Bullewijk district, on Amsterdam Southeast, characterized by industrial and office buildings. This area is also characterized by its close location with the junction between A9-A2 highways, as well as the railway line Amsterdam-Utrecht. The Architect who designed this hospital is OPERA Amsterdam, Amsterdam. It was designed on area equivalent $1,100 \mathrm{~m}^{2}$ in the year 2005 and completed in the year 2015. See as represented plates 1 and 2

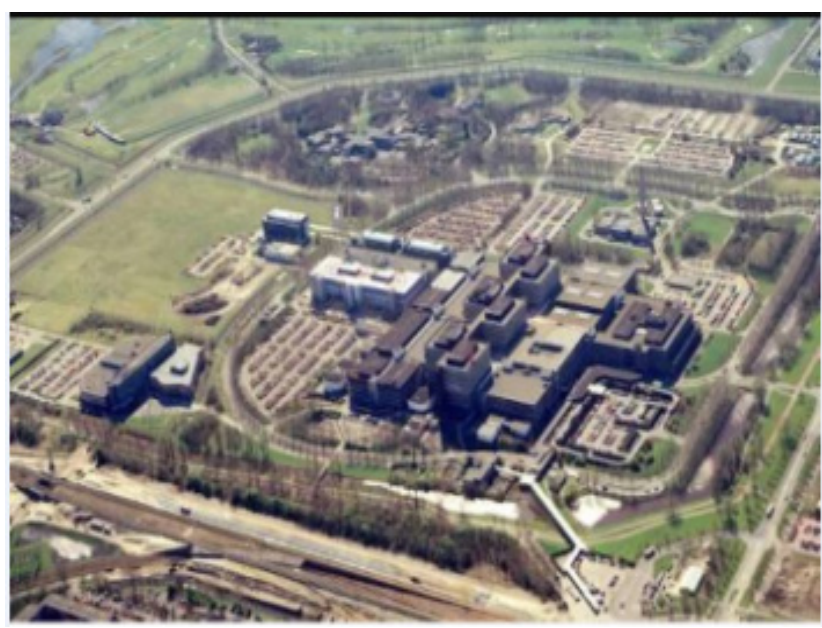

Source: www.google.com

Plate 1. Showing the Aerial View of the AMC Hospital

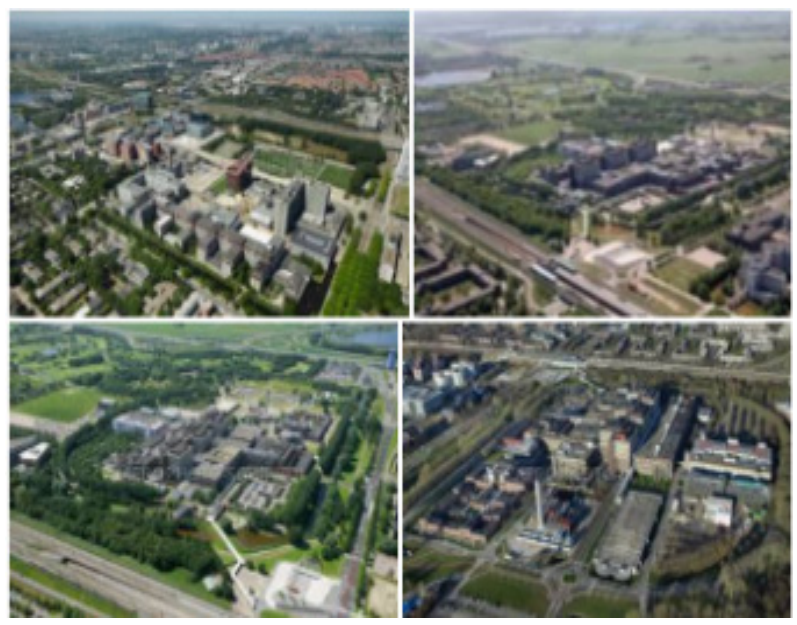

Source: www.google.com

Plate 2. Showing the Location \&Junction views of the AMC

AMC hospital construction was concluded in 1983, represents more than a building, with a set of nursing, educational and researching buildings, connected as a city as represented in plate 4 . The buildings are connected in the ground floor, by streets and squares, which provide a commercial courtyard, with terraces, restaurants, shops and art. The hospital is located in the central higher building set, occupying the 8th and part of the 7th floors as represented in plate 3. In terms of accessibility, the hospital is mostly expected to be approached by car, train or bus, providing a wide parking area on the ground floor, and a bus and train station with a covered path for direct entrance in the hospital.

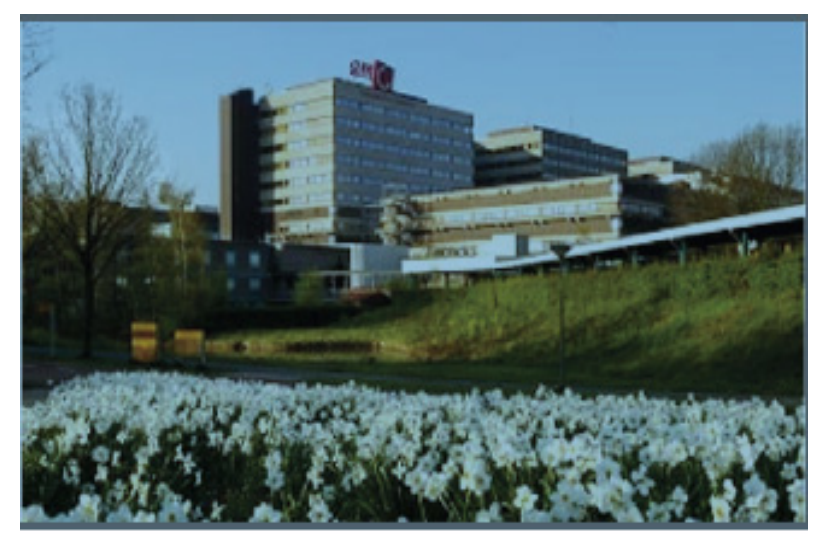

Source: www.google.com

Plate 3. Showing the floor Level of the AMC Building

Generally, the functional organisation is divided in levels of intimacy: the most public space is the corridor, which is accessed by people of the different wards; the wards that can be seen as a home, offering lounges, family living rooms or playrooms for ward's users; and ultimately the most private space, the child room. Also, the wards are mostly divided by age in order to obey the different age groups' requirements, which also allow more appropriate interactions between hospitalized children and 
children/health carers. In addition, Emma Plaza houses a great variety of functions and physical facilities such as the cinema, info centrum, psychiatry, school, sport centrum and public toilets facilities.

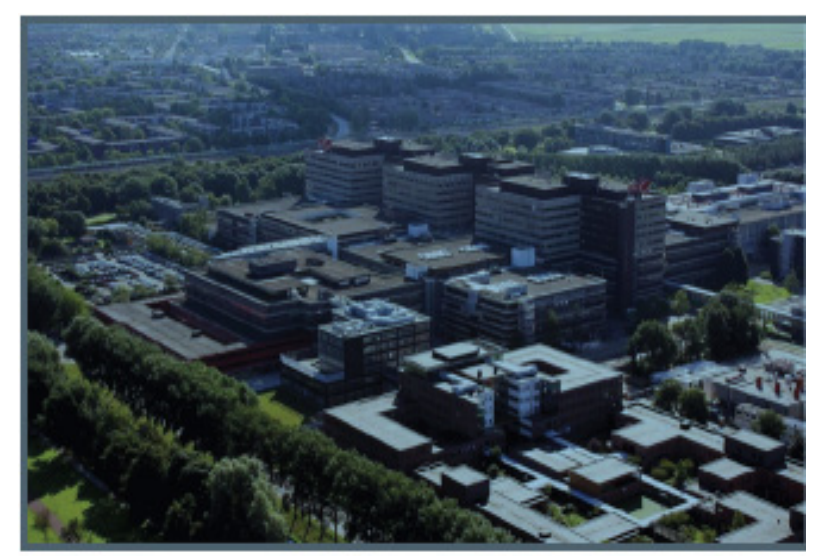

Source: www.google.com

Plate 4. The Aerial view of the AMC Building as Connected to Other Facilities

\subsection{Privacy within Emma Children's Hospital}

According to Pinhão, (2016) privacy and socialization are important factors and should be balanced in an effective way to offer a better hospital environment. However, the care units are mainly divided by age, excluding the oncology and intensive care wards that need a specific medical care and vigilance. At Emma Children's Hospital there is a predominance of single rooms' layout, the number of common bedrooms increases with age, as parental dependence decreases. (Pinhão, 2016). The single room layout is adapted to two and four patients' rooms, multiplying the amenities for each one. The other main difference is the amenities dimensions that vary with the age group. For example, the babies' rooms need less space due to the smaller bed size, and the bathroom facilities in infants ward are also smaller, according to children's heights. However, when treatment are carried out in a single bedroom space the staff are associated with better environment, less staff interaction and visibility of patients, this enhance the level of privacy enjoyed by both the caregivers and the patients, see figure 3 and plate 5 as represented. Generally, the room layout presents an inboard bathroom on the footwall, leaving a free visual connection staff-patient and offering a wide panoramic view through the outside. Several design strategies can also be identified in order to attribute different users' Zones for privacy. First, the sections demonstrate an increase on ceiling heights, with the lowest in the entrance for staff area, followed by the patient zone, and the highest correspondent to the family area. These suspended ceilings use a high absorbing material, also flexible to introduce ceiling lights, as the one above the bed. However, the different heights only predict the position of the group users, being complemented by the plan inputs about users' action area. It is possible to identify two different floor colors, which divide the right and left bed sides. One side corresponds to staff working area and the other to family stay.

Finally, the curtain is another element that contributes to the space division and privacy within the building (Pinhão, 2016). However, two different spaces can be defined: the entrance area, where staff members can prepare medication, disinfect hands or clean the wet areas (bathroom and sink), without disturbing patient and family; and the room area is transformed in a more private space, where family can be with their child without feeling observed. The general appraisal revealed that patient's parent desire privacy by preferring single rooms as they often need to escape from the type of environment where they see their ill child suffering. Thus, even though there are plenty of lounges for family purposes in the seventh and eighth floors, they prefer to go to the ground floor or outside to feel in a completely different space. Generally, the paediatric hospital's degree of privacy enjoyed by both patients and staff is considerably very good and still need more improvement on design for privacy.
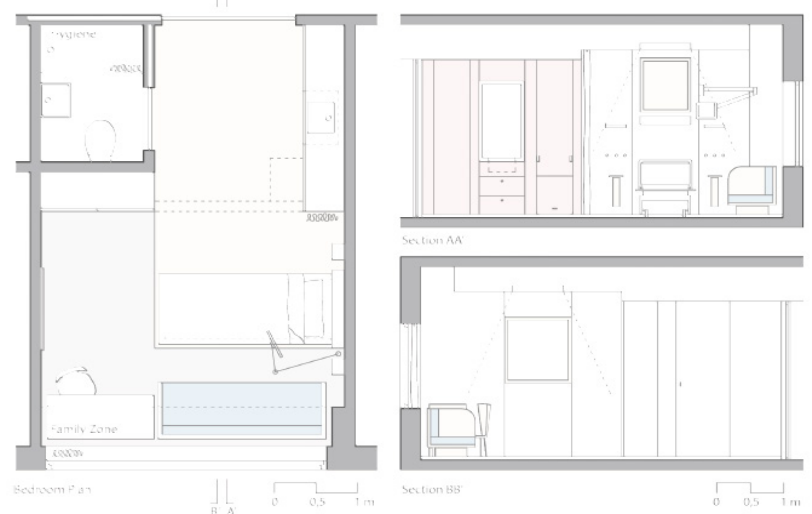

Source: Pinhão, (2016)

Figure 3. Showing the Typical Single Room Floor Plan \& Sections

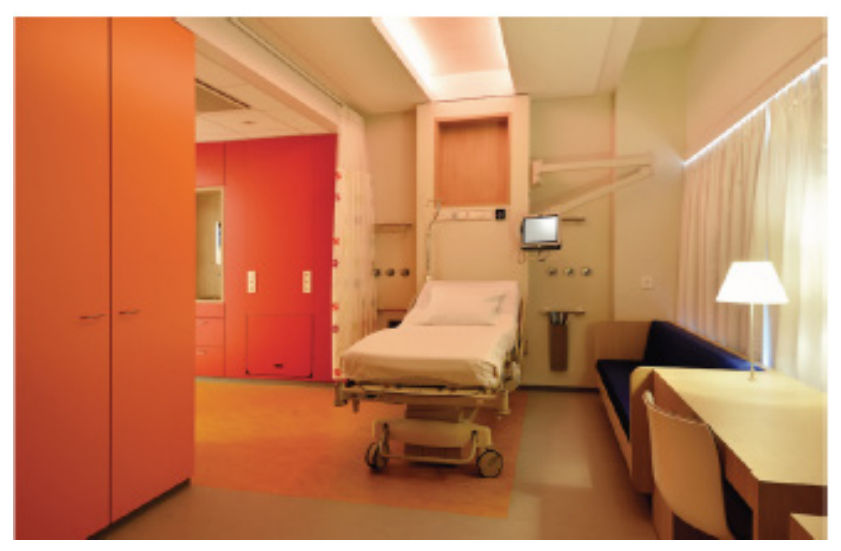

Source: Pinhão, (2016)

Plate 5. The interior furniture of Typical Single Room 


\subsection{Proximity of Facilities in Emma Children's Hospital}

The proximity of patients and staff is considered to be absolutely good considering the traveling distance to their nearest hospital and the distance travelled between the hospitals physical facilities. The northern part of the building accommodates the offices and business facilities; the western part of the building accommodates the Holendrecht residential area. The building has a good location and accessibility not too far from the users (patients and staff residential area). Just in front of the main entrance is located a general reception see as represented in plate 6 and figure 5. Appraisal based on traveling distance between the hospitals physical facilities gives access to two different wards such as ward H7 for Babies or Staff wards, ward H8 for Intensive Care or Day Hospital and staff wards, G8 for Emma plaza or Children Wards and F8 for the Teenagers or Oncology wards. See as represented in figure 4 and plate 7 .

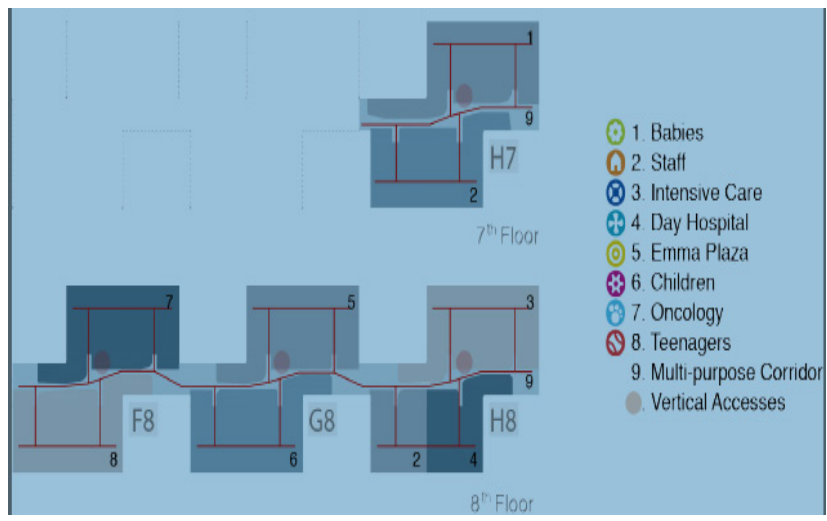

Source: www.google.com

Figure 4. Showing the proximity of different types of Wards

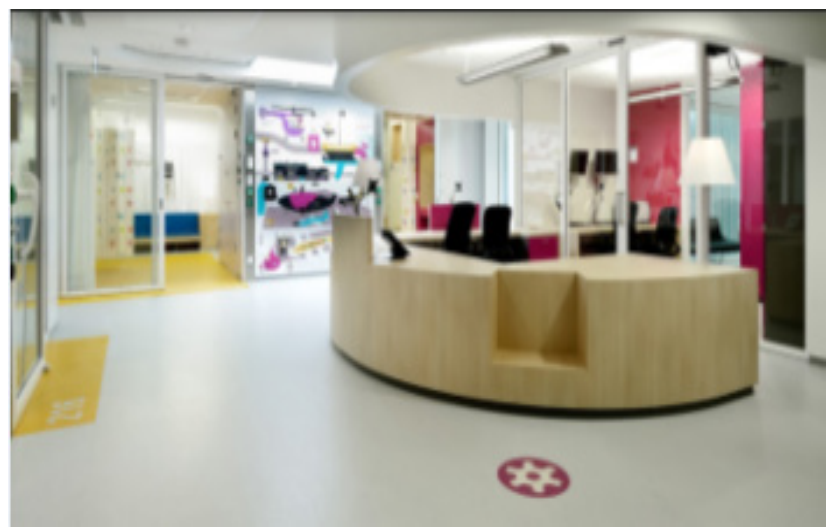

Source: www.google.com

Plate 6. Showing the functional movement flow in the Reception

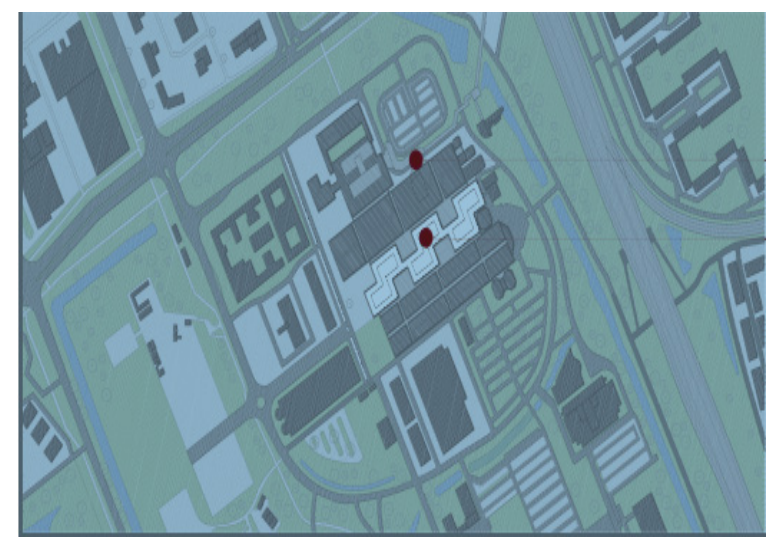

Source: www.google.com

Figure 5. Marked Red is showing the entrance to the Building

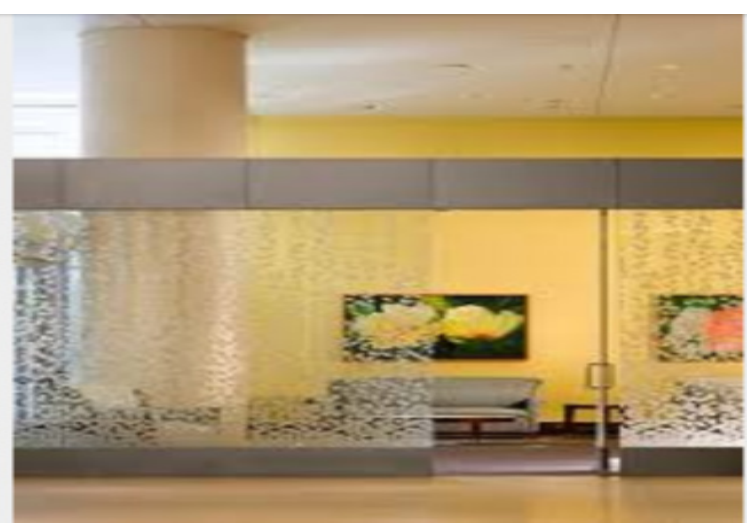

Source: www.google.com

Plate 7. Showing the Hospital Lounge

The Family Living Rooms are equally distributed and located in all wards along the main corridor. Rooms situated on both floor ends aids quick accessibility of Teen's lounge, IC Family Living Room; (see as represented in plate 13.) and the Garden Room. Even though these lounges belong to specific wards, children from other wards can also use them; see as represented in plate 14. However, this is arrangement is in agreement with the principle of design for proximity which stated that proximity should be done in accordance with the principle of proximity of perceptual organization which stated that, stimuli or objects that are in close proximity to each other can be clearly perceive when being grouped together.

In Academic Medical Centre, internet facilities are easily accessible through WI-FI in all hospital areas. Laundry room is not offered in this hospital but only available for parents who are housed in the Ronald McDonald House nearby. Generally, the proximity of the Emma plaza or Children Wards to other departments within the Academic Medical Centre is considerably deigned well most especially the proximity of the work area to staff offices, consulting offices \& nurses station and also the proximity of the each wards spaces to laboratory and diagnostics facilities within the hospital environment. This is important because Proximity toward long distances between different working areas have negative impact on 
staff performance and quality of healthcare delivered to the patients. The staff usually covered a very long walking distances during their shifts. The information is represented in plate. However, the design for proximity of the physical facilities in terms of easy accessibility to both staff and patients is considerably good. Facilities are well located and not too far from each other.

\subsection{Wayfinding within the Emma Children's Hospital}

Generally, the full appraisal of Emma Children's Hospital shows that sign-post is made available for the users to locate the entrance to the children hospital. Also, some of the internal spaces and external facilities were clearly labeled; see as represented in plate 8 and figure 6 respectively. However, the sense of approaching the children's department can be described as entering a completely different atmosphere, full of light, color and a panoramic view to the outside world. This view escorts the users along all façade, which matched with the rooms' walls transparency, provides a constant connection with the outside. The stairways and parking lots leading to the next floor within the department are clearly accessible. Facilities such as pharmacy wards, treatment, examination, consulting counseling rooms, waiting, reception record unit, nurse's station, operating theatre, toilet, laboratory and diagnostics facilities within the hospital environment are well labeled. In addition, the department provides a corridor that covers the length of the hospital, connecting different spaces and activities; see as represented in plate 10. One of the main important components of this wayfindings is the introduction of well labeled street in the hospital environment. It is a changeable width, creating different spaces of circulation and stay, and integrating the most public functions, such as restaurant and entertainment areas. In the elevators location, the corridor also expands creating a hall where graphical signalisation is printed on the floor; see as represented in plate 9, allowing a child friendly interpretation and easier way finding.

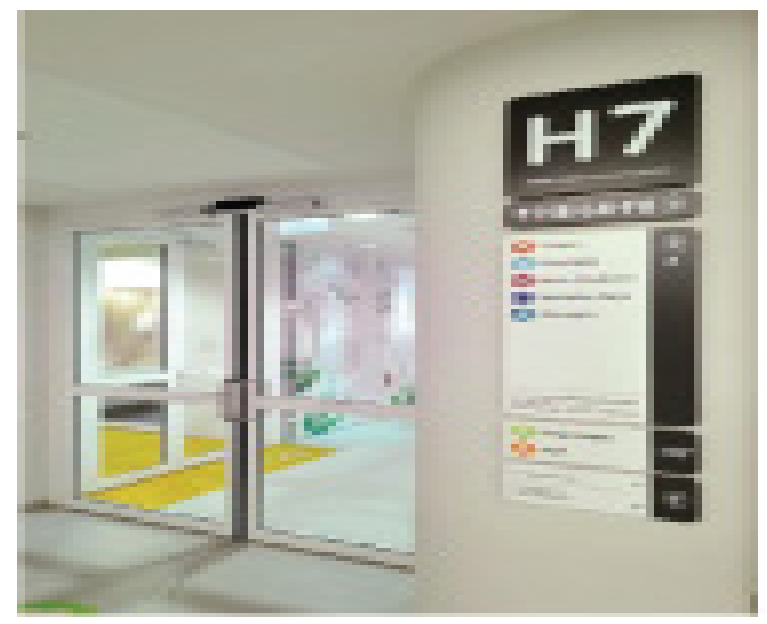

Source: www.google.com

Plate 8. Showing the Entrance Door, labeled and Sign post of Way findings

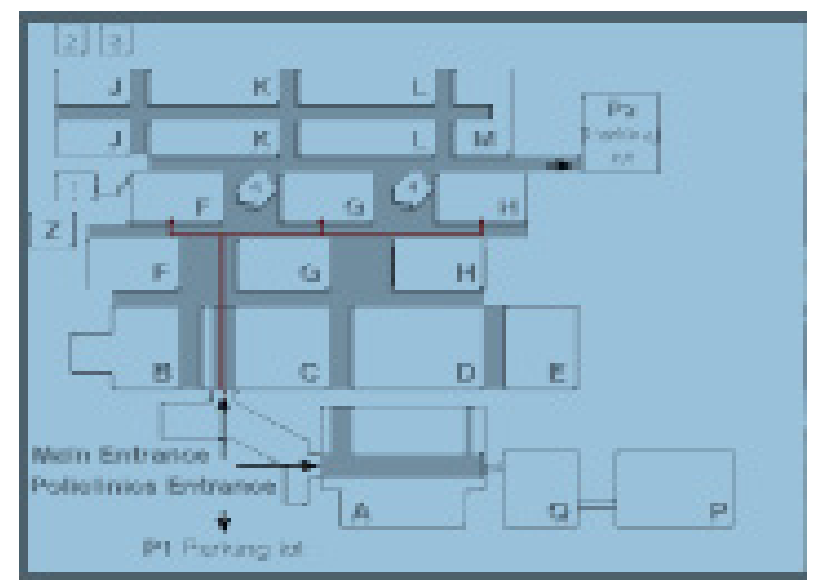

Source: Pinhão, (2016)

Figure 6. Showing proper labeled for Way findings

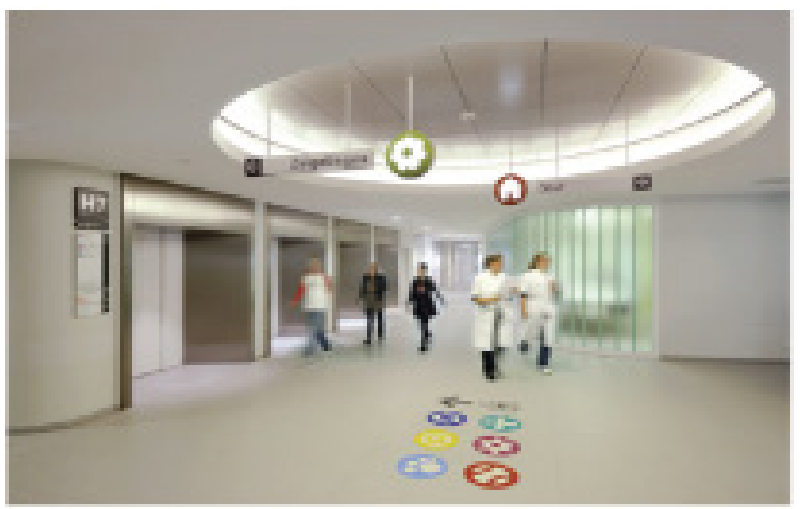

Source: www.google.com

Plate 9. Showing the Graphical Signalization printed on the floor

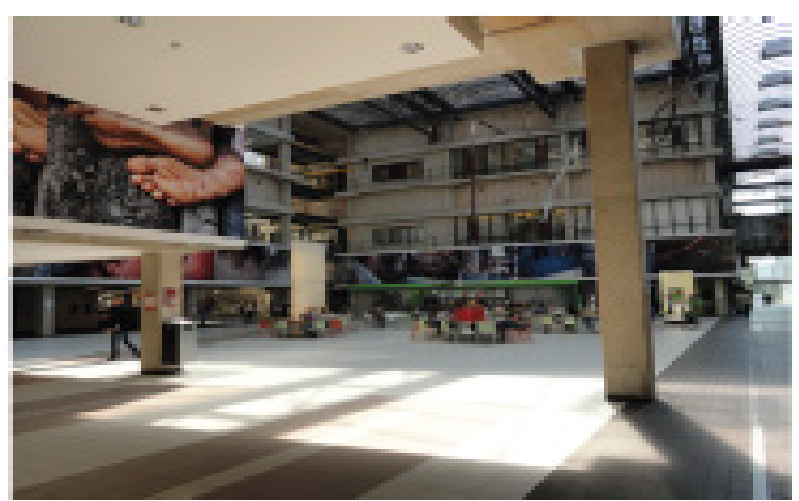

Plate 10. The interior view of the Corridor and Circulation For easy Way find that connect different spaces for easy Wayfindings

Considering the physical appearance, the wards are represented with different colors and themes, and present a semi-public corridor, surrounded by bedrooms. The internal part of the corridor accommodates the technical, staff rooms, reception and small lounges. By entering in the main entrance, a completely new reality is set out. Within the corridor, four public lounges take place, strategically located in relation with the wards nearby. The Fish Lounge is near the oncology ward and offers a wide space to sit 
comfortably; see as represented in plate 11. The playground shares the same space, in connection with the infants' ward. This lounge allows children to jump, hide or climb and also offers an interactive screen; see as represented in plate 14. Furthermore, the sidewalls are filled with benches for parents to monitor their own children. The above appraisal is an evidence that the wayfings within the hospital physical facilities is considerably to be good because of availability of wayfindings facilities such as adequate labeling of spaces, location of sign posts in some strategic places within the hospital environment, but more can still be done to enhance the performance of the way finding facilities for the children hospitals in the future.

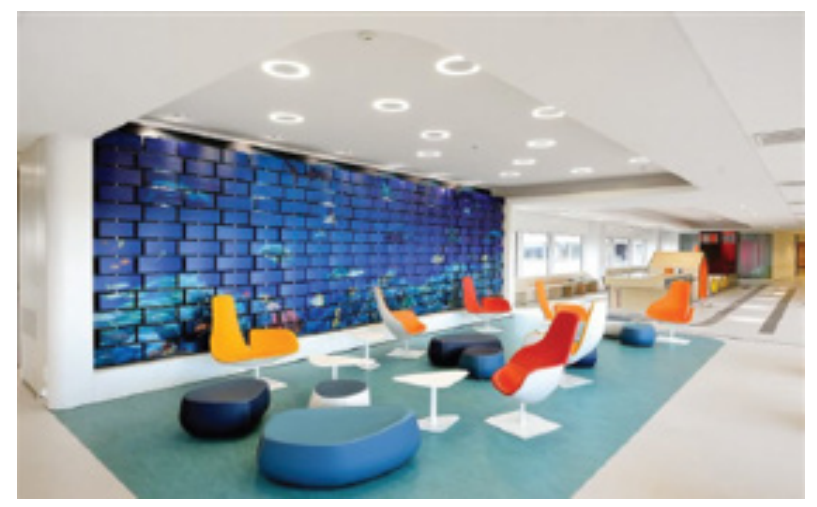

Source: www.google.com

Plate 11. Showing the Fish Lounge

\subsection{Flexibility and Adaptability of Spaces}

According to Bobrow \& Thomas, (2000) and Gallant, el al., (2001), the flexibility and adaptability design of hospital physical facilities that allows changing acuity and care need of patients contribute to decreased medication errors and falls in the facility (John, Ronda, Mike \& Murphy, 2001). However, the Academic Medical Centre plot have area allows for future expansions and upgrades. They defended the introduction of picture boards, lockable storage, shelves and capability of changing the environment with one's personal taste enables patients to be surrounded by familiar things of value.

Adaptability and Flexibility became especially important for long-term hospitalizations, since this adaptability level allows patients to change their personalized elements whenever they want. At the Family Living Rooms, some public lounges were designed, in order to provide a space for children and their families to socialise, play, eat or even relax together. The last lounge houses the restaurant, info centre and silence room. The restaurant is connected with the Emma Plaza and is widely used by all hospital children and respective families; see as represented in plate 12 . In addition, there are several shelves and a wardrobe to keep personal belongings, and a board where motivation pictures and cards can be placed.
The room also provides a sofa bed for a parent to stay overnight, a table with a chair and electronic device placed near the bed. However, from this study it is considered that the flexibility and Adaptability of spaces within Emmal Children hospital is considerably very good, but more can still be done in the subsequent design for the children hospitals in the future.

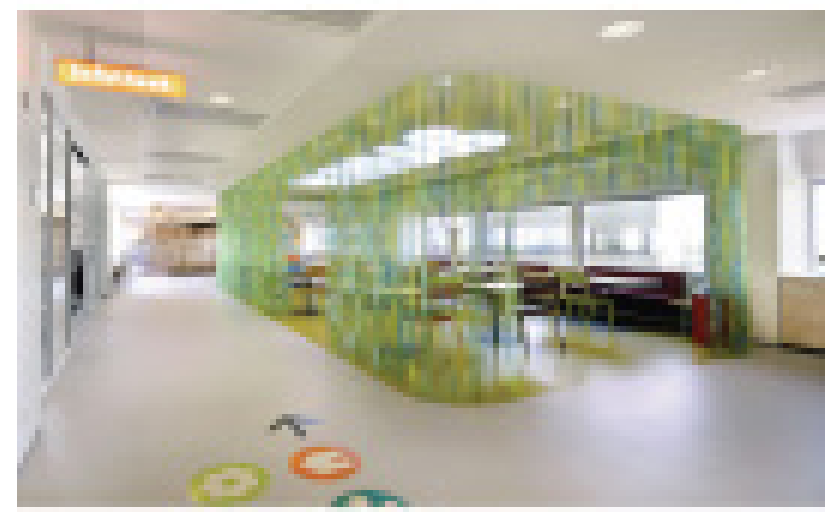

Source: www.google.com

Plate 12. The restaurant

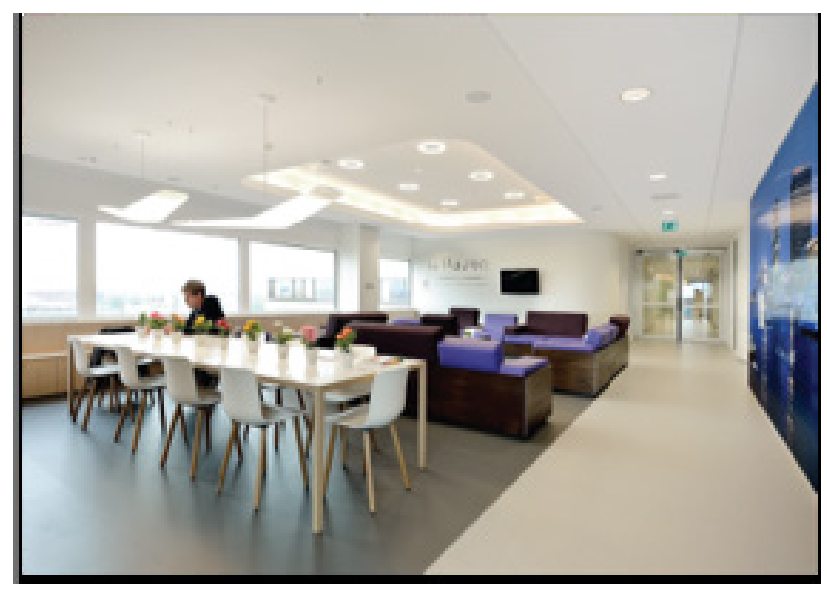

Source: www.google.com

Plate 13. The IC Living Room
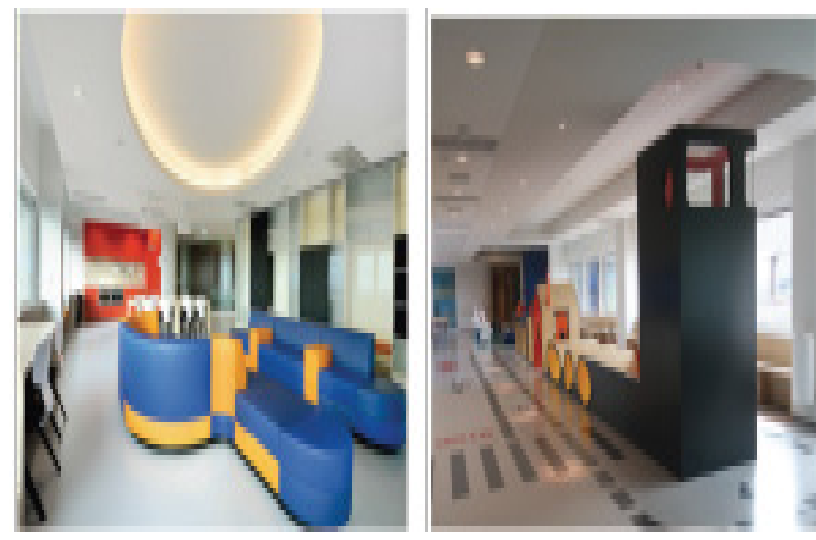

Source: www.google.com

Plate 14. The Play Ground \& Silence Lounge 


\section{Southwestern Nigeria Healthcare Physical Facilities: Lesson from Netherland Children Hospital}

Nigeria, in the past few years has experienced some worsening of child mortality. This can be explained by the persisting low numbers of births occurring in health facilities and the low number of births attended by trained healthcare service providers. As at 2003, two third of the births in Nigeria still occurred at home. In addition only slightly more than one-third of births in are attended by doctors, nurses, or midwives. In the year 2000, the maternal mortality ratio in Nigeria was 800 per 100000 live births. It is apparent through the elevated mortality rates that the lack of access to good physical environment, well designed spaces interm of proximity, privacy and wayfinding and ultimately the use of quality delivery services is an issue of immense importance in Nigeria. Problems such as obtaining money for treatment, distance to health facility (proximity) are some of the difficulties observed in describing difficulty with accessing healthcare in Nigeria. About 5.3 million children are born yearly in Nigeria that is about 11,000 everyday. One million of these children die before the age of 5 years. This statistical representation shows a very serious challenge in the Nigerian healthcare structure. The children healthcare should be treated as an important part of national development in order to encourage growth and stability.

Politically, Nigeria is divided into six geopolitical zones (South-West, South-South, South-East, North Central, North-East, North-West) as indicated in Figure 7. However, the study will be carried out in South West geo-political zone. The southwestern part of Nigeria is domiciled by the Yoruba people, who are a highly researched ethnic group in Africa and are bounded together by a common progenitor called Oduduwa. They have a common language, and a rich spirituality. The southwestern parts of Nigeria consists of Oyo, Osun, Ekiti, Ogun, Ondo, and Lagos states as indicated in Figure 8. The south-western, Nigeria consist of both private and public University Teaching Hospitals, located at almost every state in southwestern geopolitical zone of Nigeria.

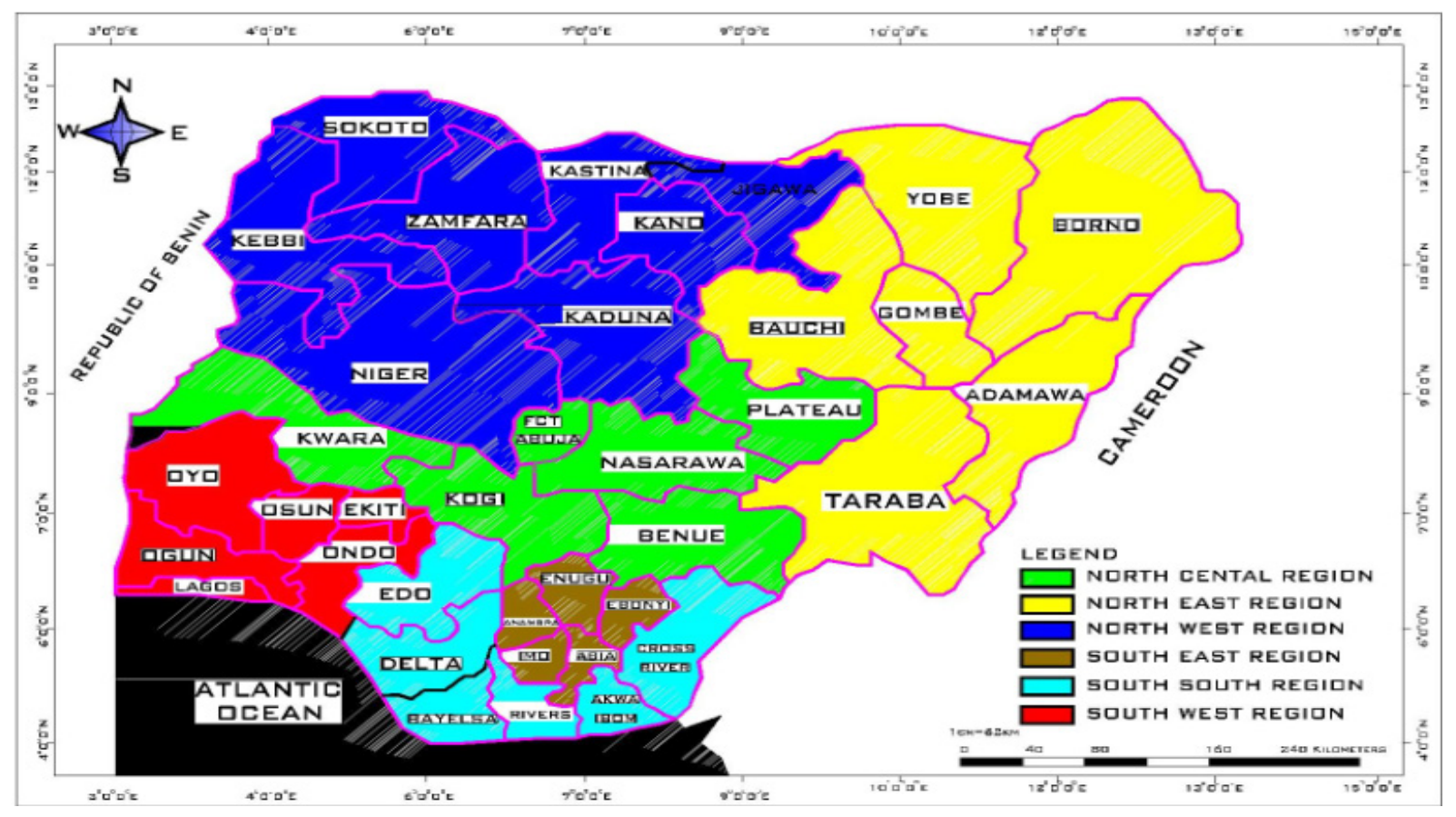

Sources: http//www.nigerinmuse.com (Digitalized by the Author)

Figure 7. Map of Nigeria Showing the Six Geopolitical Zones; 


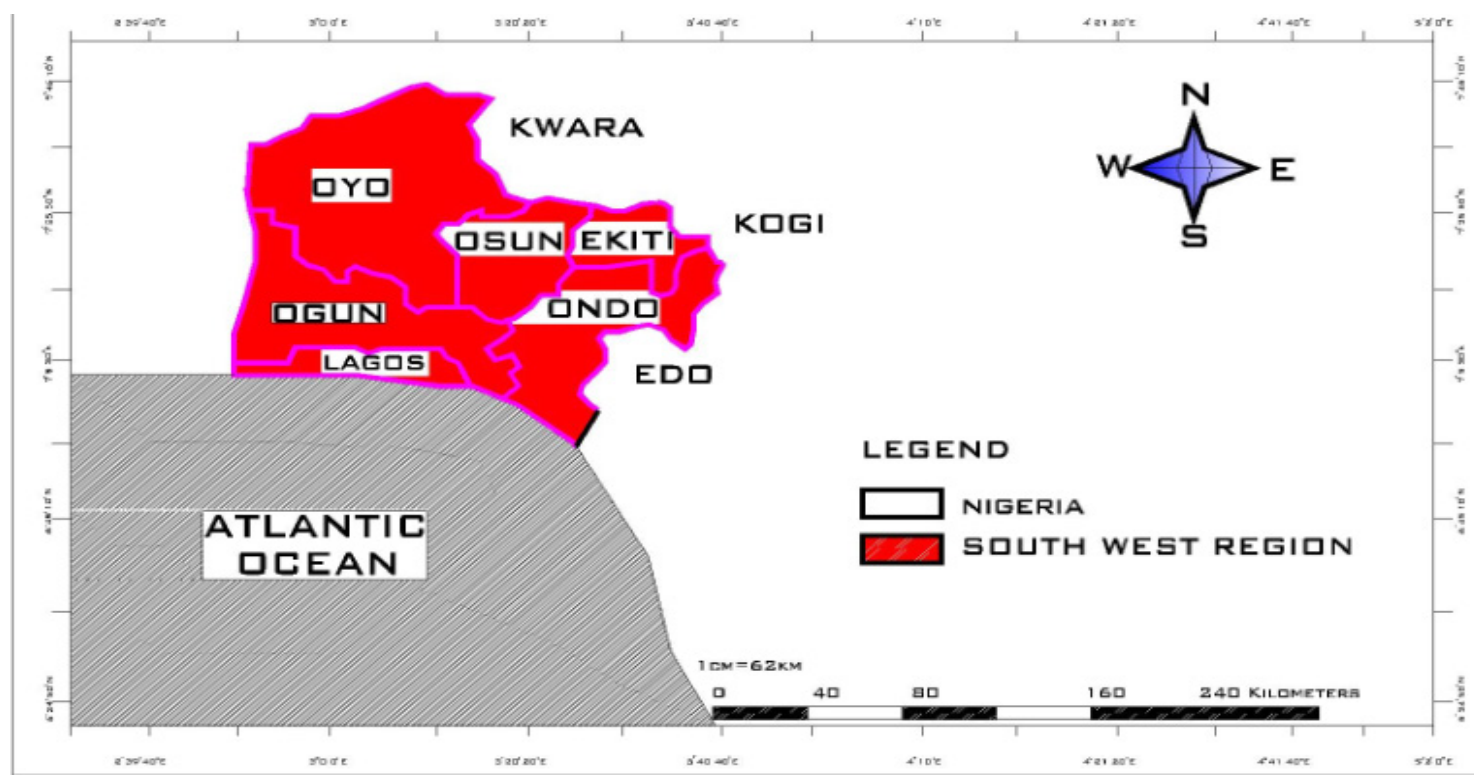

Sources: http//www.nigerinmuse.com (Digitalized by the Author)

Figure 8. Map of Nigeria Showing the Southwestern parts of Nigeria

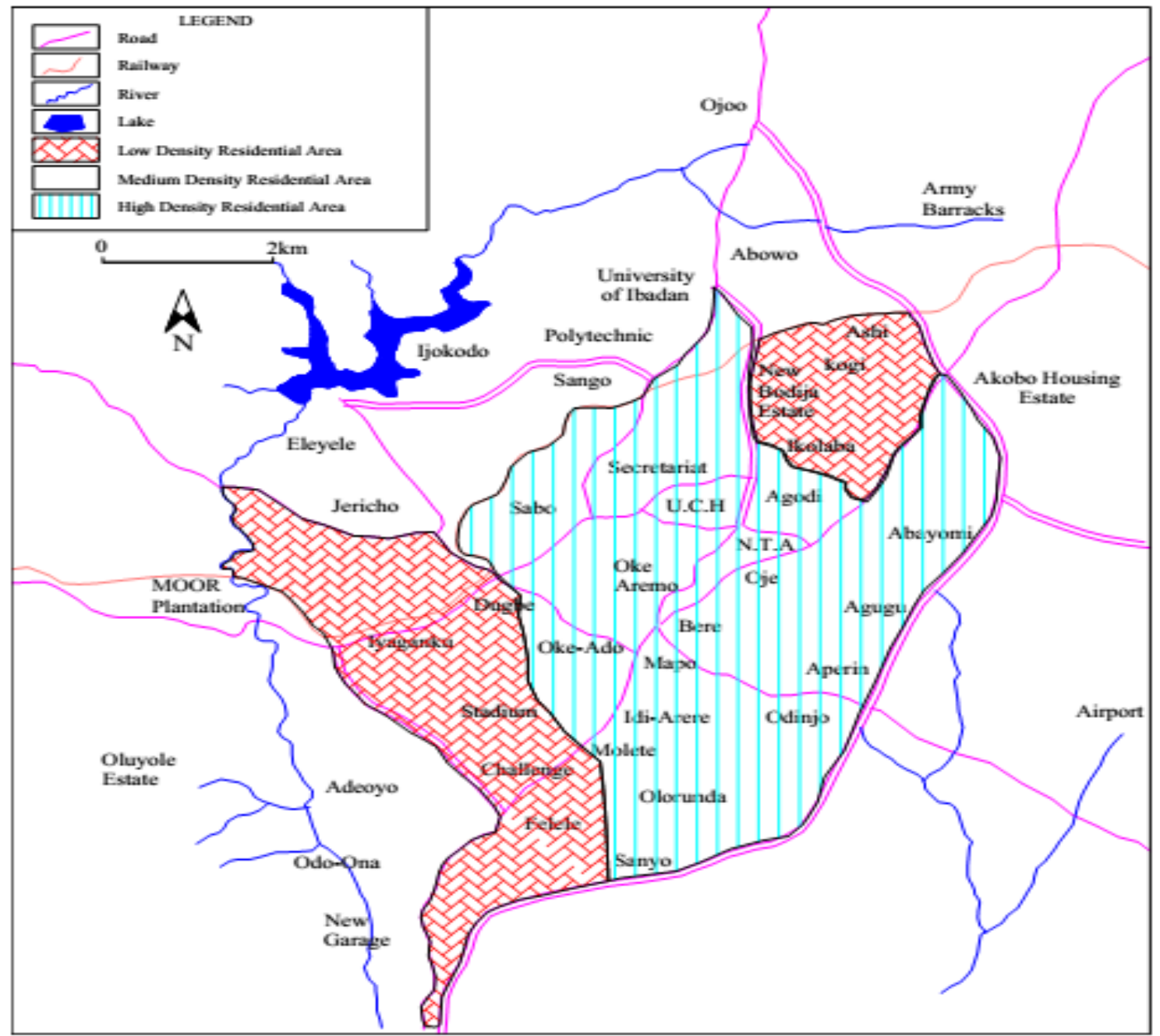

Sources: http//www.nigerinmuse.com (Digitalized by the Author)

Figure 9. Map of Ibadan, Oyo-State, Nigeria; showing U.C.H 
In an attempt to critically appraise the healthcare deigns facilities in southwestern Nigeria, University College Hospital in Ibadan was choosing for the appraisal as indicated in figure 9. This is because is the first teaching hospital in Nigeria established by an act of parliament in November 1952 in response to the need for the training of medical personnel and other healthcare professionals for the country and the West African Sub-Region. Also, Ibadan where the Teaching Hospital is located remains the largest city in Nigeria. The hospital also, has largest patronized and best professional staff proving care for the children. Its spatial organization which is based on standard paediatric centre design with the modern facilities, equipment and services used in the hospital is worth studying. Based on this reason; the appraisal of this University College Hospital can be used to appraise the situation of the current healthcare physical facilities in Southwestern, Nigeria.

\subsection{General Description of the University College Hospital (UCH), Ibadan}

Base on proximity to both the patients and the staff, the University College Hospital (UCH) was strategically located at Ibadan and the physical facilities development of the Hospital commenced in 1953 in its present site and was formally commissioned after completion on 20 November 1957. The initial design of the new teaching hospital by Mr. Alexander Gray, F.R.I.B.A the Consulting Architect (Source; Record Unit, UCH). However, the hospital has evolved to accommodate about 60 departments among which are the department of Pediatrics. The management of the hospital spurred by the Federal Government efforts in refurbishing the teaching hospital has taken steps to widen the scope of services provided by the resuscitation of the open heart surgical procedure of the Hospital as indicated in plates 15 and 16 .

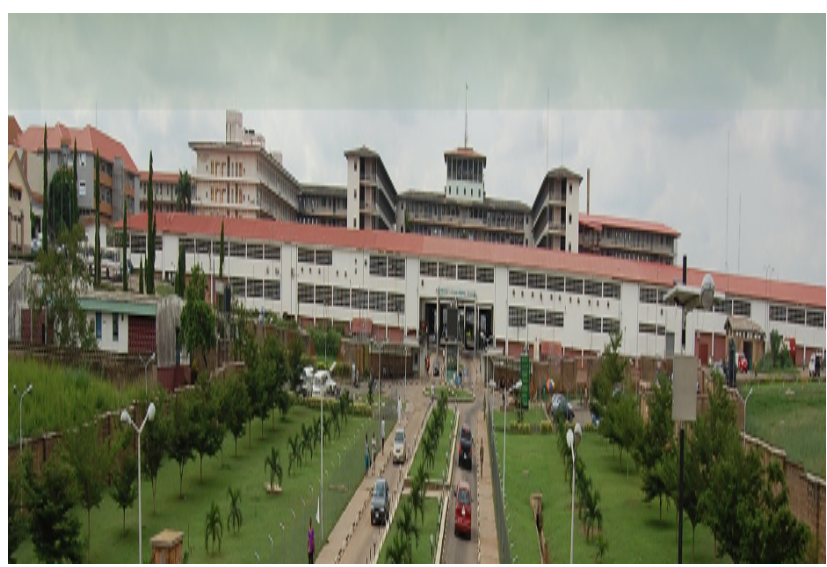

Source: Authors Field Work, 2018

Plate 15. The Front View of the and Main accessibility of UCH

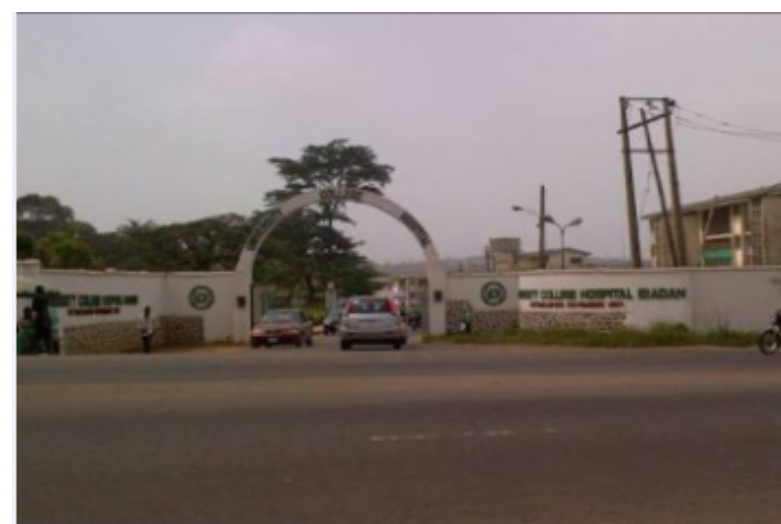

Source: Authors Field Work, 2018

Plate 16. Alternative Exit of the Hospital

\subsection{The Paediatric Children Physical Facilities in UCH, Ibadan}

Although the Department of Paediatrics was formally created in 1962, paediatrics as a specialty had always existed in the UCH. However, this was as a unit within the Department of Medicine as represented in plates 17, 18, 19 and 20. As the first academic Department of Paediatrics in Nigeria and West Africa, the teaching of facts, skills and attitudes essential for the effective care of children has always been done. The pediatric department of the University Teaching Hospital includes the following physical facilities which facilitate the health care system in the hospitals. The facilities include Otunba Tunwase Children's Emergency Ward, Neo natal ward, Isolation ward, Children's clinic and Inpatient wards among others; see as represented in plates 2122 and 23. The children's clinic located on the first floor of the hospital is used as the outpatient unit of the pediatric department. Most spaces within the department are adequately naturally lightened and ventilated with few exceptions in the children's clinic such as the medical record room and the conveniences. The use of long wide louvered windows together with other specially designed openings in the walls allows the penetration of daylight.

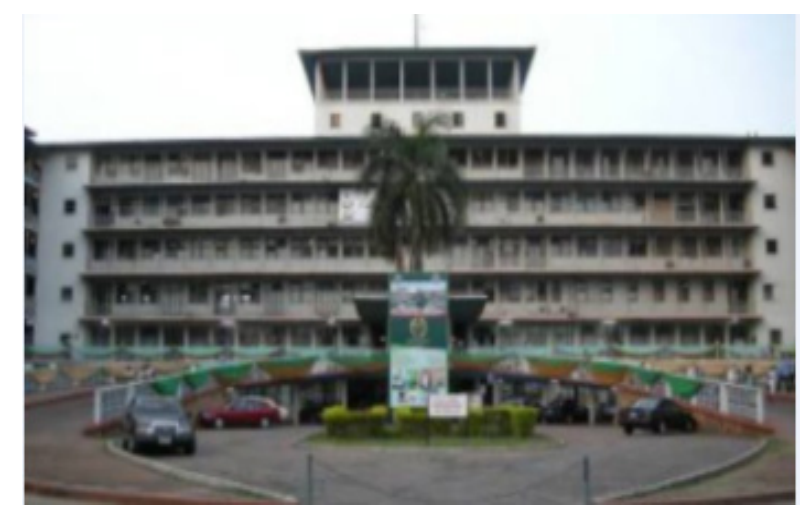

Source: www.google.com

Plate 17. Showing the Front View of the Paediatric Department 


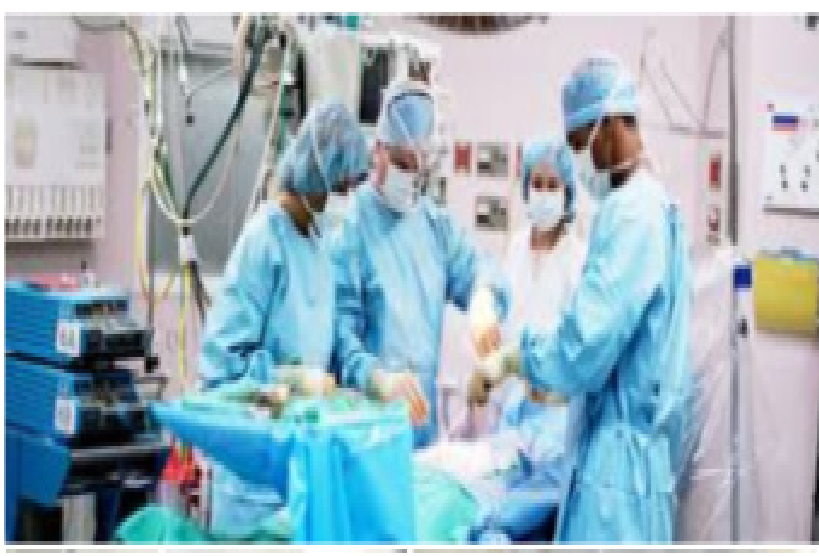

Source: www.google.com

Plate 18. Showing the Work Area of the Paediatric Department, UCH

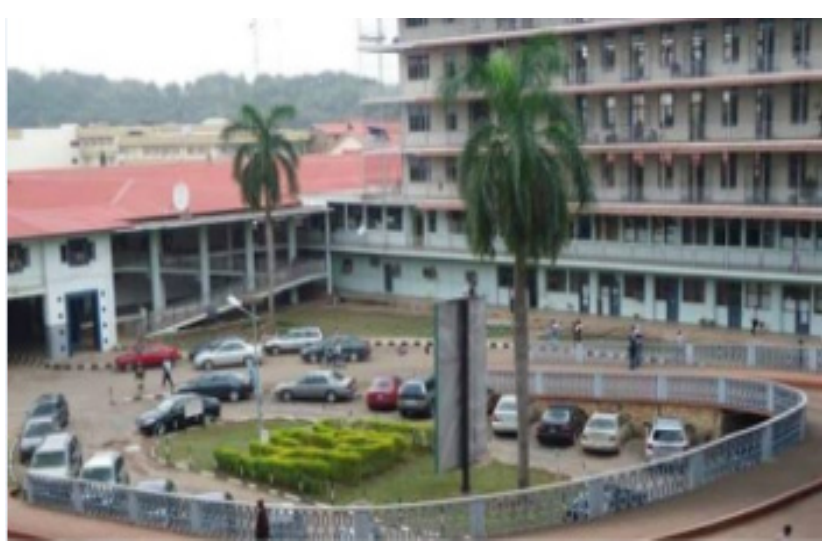

Source: www.google.com

Plate 19. Showing the Aerial View of the AMC Hospital

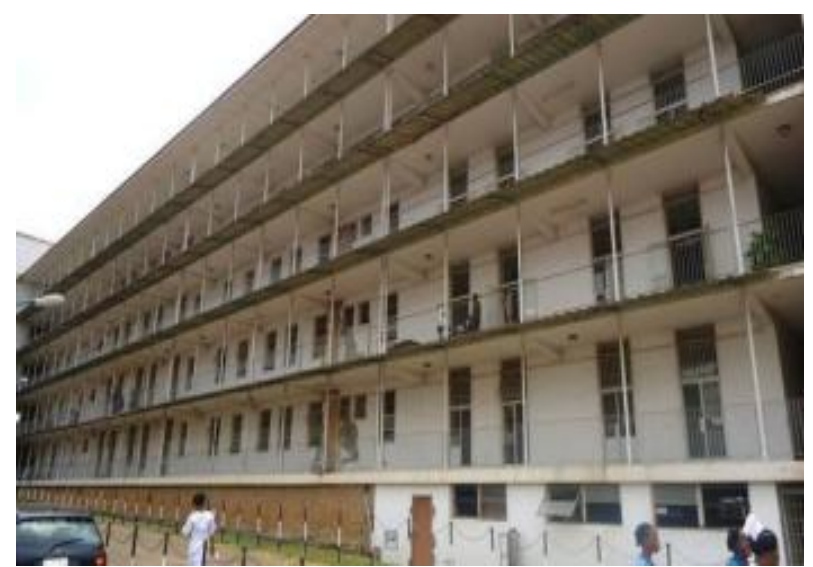

Source: www.google.com

Plate 20. Side view of the pediatric inpatient section of the hospital.

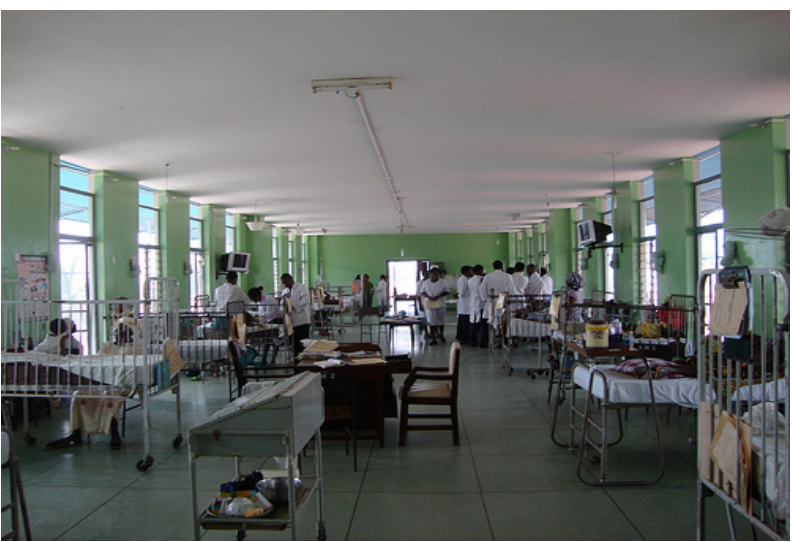

Source: Authors Field Work, 2018

Plate 21. Interior view of the emergency ward

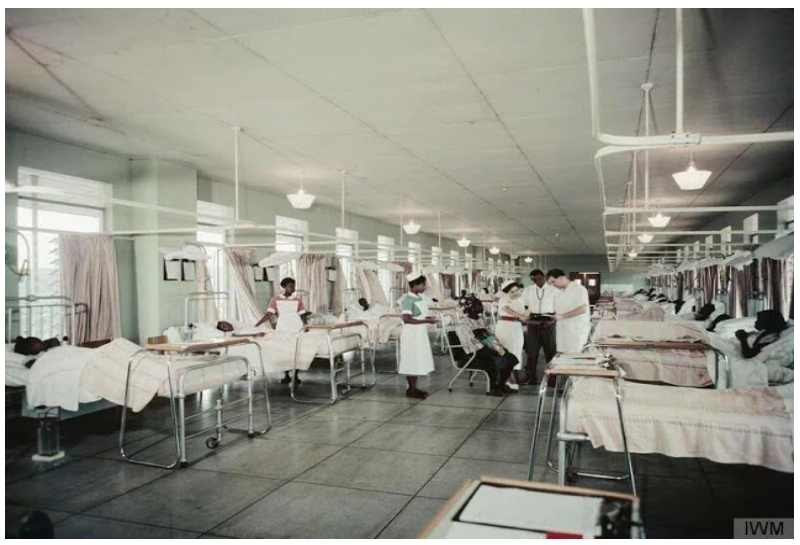

Source: Authors Field Work, 2018

Plate 22. Interior view of the Neo Natal Ward

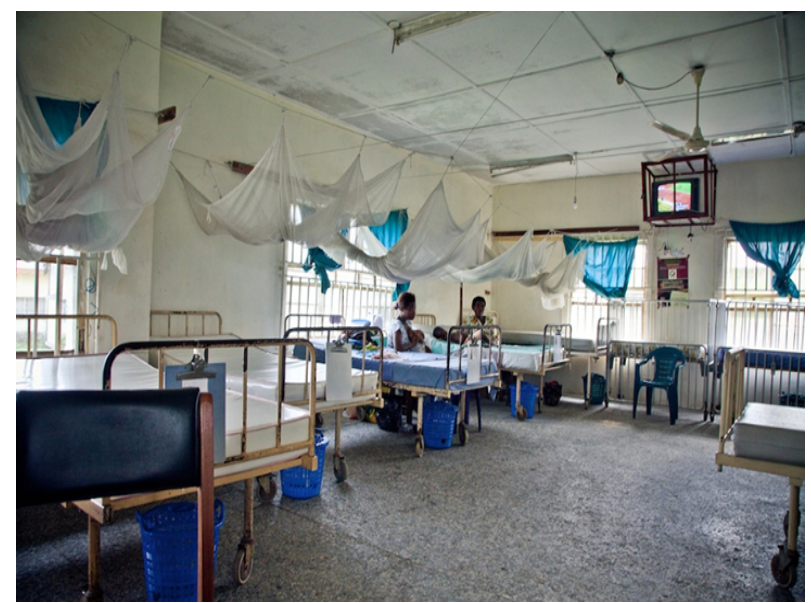

Source: Authors Field Work, 2018

Plate 23. Interior view of the Isolated ward 
It comprises of the consultation room, pharmacy, nurse lounges, medical record room, card issuance area, weighing room, injection room and changing rooms. Otunba Tunwase Children's Emergency Ward began as a Children's Emergency Room in the Medical Outpatients Department (MOP). Children who were too ill to go home were transferred to the Casualty Department together with the adults. The Department of Pediatrics took over all of the old Casualty Department, with a generous donation and re-designed by a Nigerian philanthropist, Otunba Tunwase Balogun, Children's Emergency Ward in his honors. The neo natal ward is meant to cater for the needs of children within the first 28 days of their life.

\subsection{The Design Characteristics of the Structure and Building Forms}

The hospital complex itself is a six floor building with the pediatric department occupying spaces from the first to the fourth floor for the various inpatient wards as represented in plates 24 and 25 . The department, however, shares other auxiliary facilities such as morgue, laboratories, x-ray, and other spaces with the rest of the hospital as indicated in plates 26 and 27. The University Teaching Hospital pediatric department is made up of different arms and wings which include the children's clinic, the Otunba Tunwase emergency ward, the neonatal ward, the premature ward and many others. As a result of the pediatric department being a part of the general hospital most of the sections are located across various locations within the hospital complex.

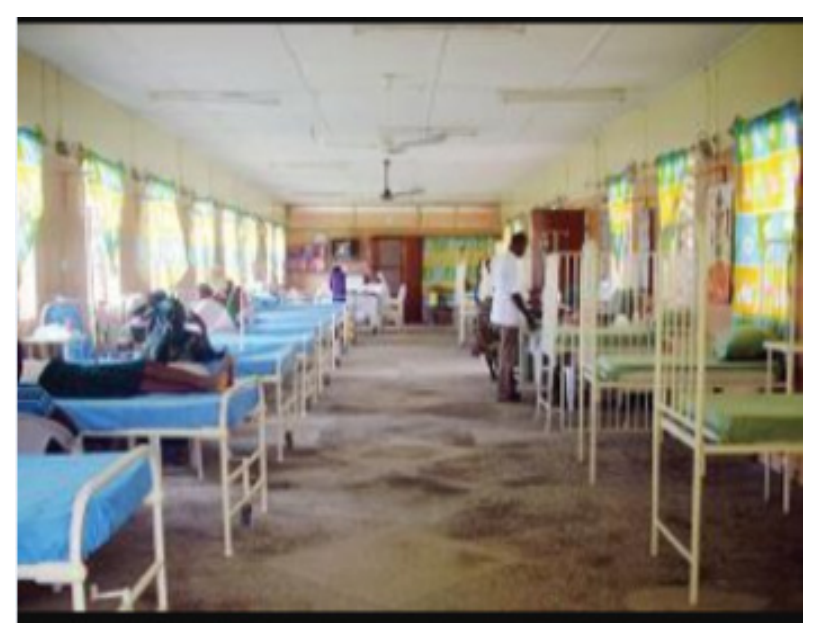

Source: Authors Field Work, 2018

Plate 24. Interior view of the Paediatric Inpatient Ward

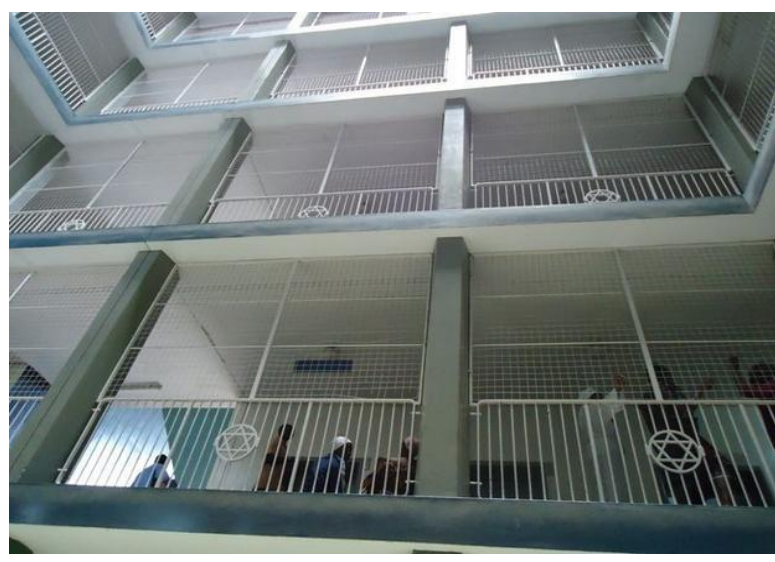

Source: Authors Field Work, 2018

Plate 25. Showing the Different Floors and Corridors to Various Wards

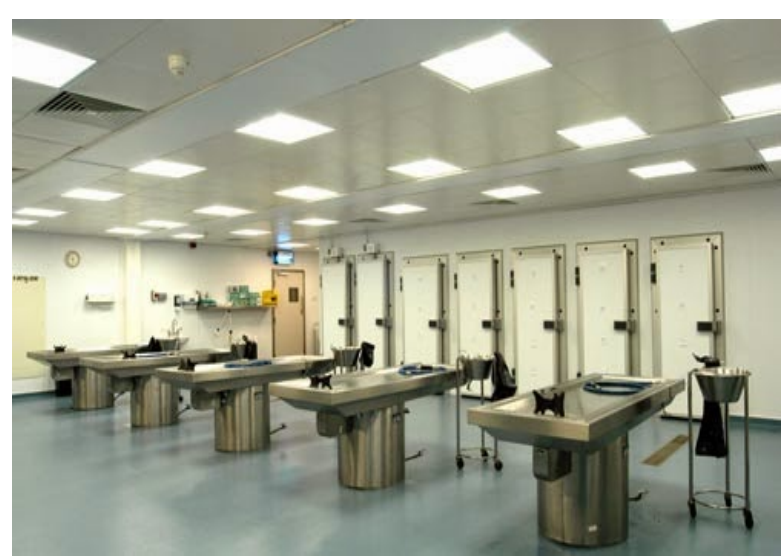

Source: Authors Field Work, 2018

Plate 26. Interior view of the Isolated ward

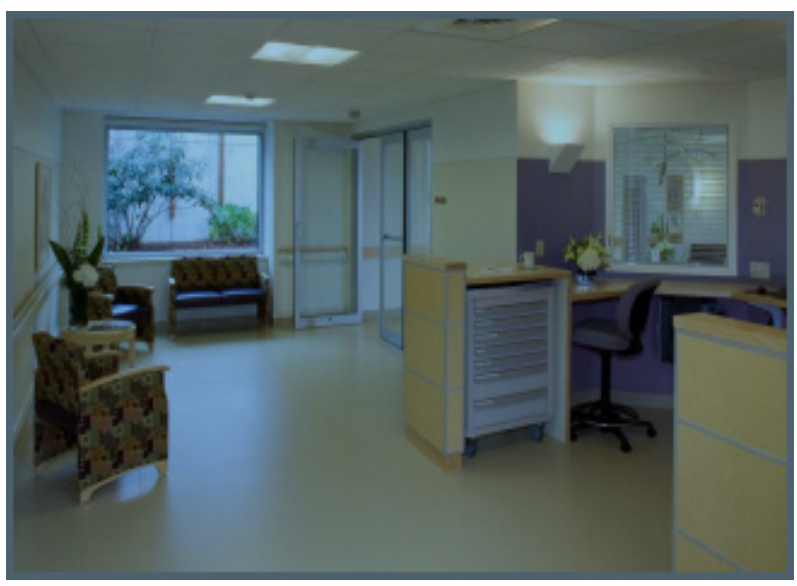

Source: Authors Field Work, 2018

Plate 27. Interior view of the Paediatric Inpatient Ward 


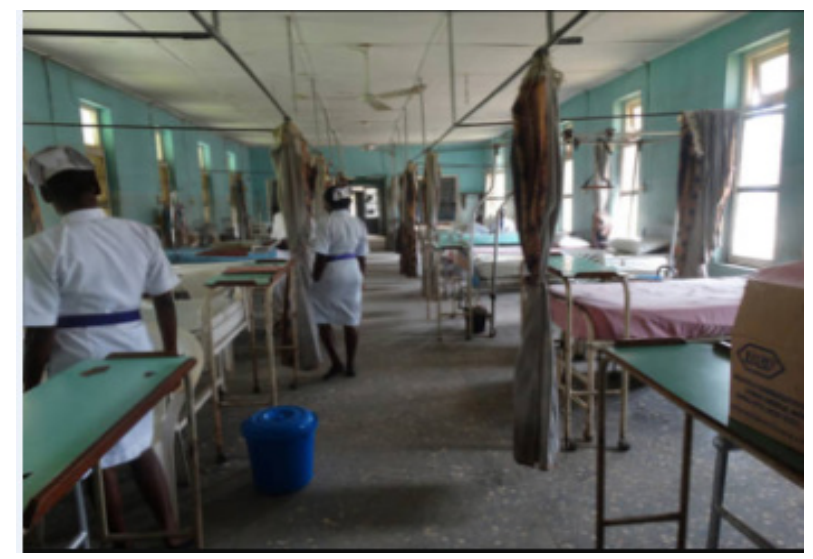

Source: Authors Field Work, 2018

Plate 28. Interior view of the Paediatric Inpatient Ward

There are good uses of natural lightening and ventilation in most spaces such as wards and work spaces in the department and the hospital design is disabled friendly as provisions are made through the inclusion of ramps and lifts. However, the appraisal of the facility design shows that: all corridors are wide enough to allow for Movement flow/Pattern of the patients and staff for human traffic and rare cases of emergency, but are not design for children friendly, because it lack aesthetic such as provision of good colour environment, art work, wall papers among others to facilitate heath and staff performance. The ward design in term of space size, proportion, beauty, attractiveness, decoration \& Artwork are not good enough compare with what is obtained in the developed world hospitals. See as represented in plate 28 .

\subsubsection{Proximity within the Physical Facilities}

Generally, proximity of the paediatric department to other department within the hospital environment is considerably good, but more design considerations for proximity could still be done for future design. Proximity toward long distances between different working areas has negative impact on staff performance and quality of healthcare. The design for proximity in the paediatric department of University College Hospital, Ibadan is considerable good; however, the facilities are centrally and strategically located at the core area within the hospital environment. Also, proximity of internal facilities to each other is bad as the distance between the outpatient clinic and inpatient wards are too far apart and barely functional. The department exhibits long corridor which contributes to noise volume and make way finding more difficult as indicated in plate 25 . Also, the proximity of nurse's station to patient wards in the hospital created expected outcomes such as less working by nurses, more time at bedside, less acute stress, more productivity and enhances collaboration which means there are good design considerations for proximity of patients to the nurses' station.

\subsubsection{Privacy within the Physical Facilities}

Privacy of both the staff and patients is one of the design related issues identified as a problem experience within the paediatric department in UCH, Ibadan. Through brief interview, lack of adequate privacy were identified which has resulted to increase noise, insufficient care, improper control of own environment and lack of satisfaction with the hospital physical facilities. For example; having personal single room enhances patient privacy, personal storage and control of infection among the users as indicated in plate 29. However, the amount of visual privacy enjoyed in your working area such as counseling operation theatre, examination, and offices were appraised very low as indicated in plate 30 .

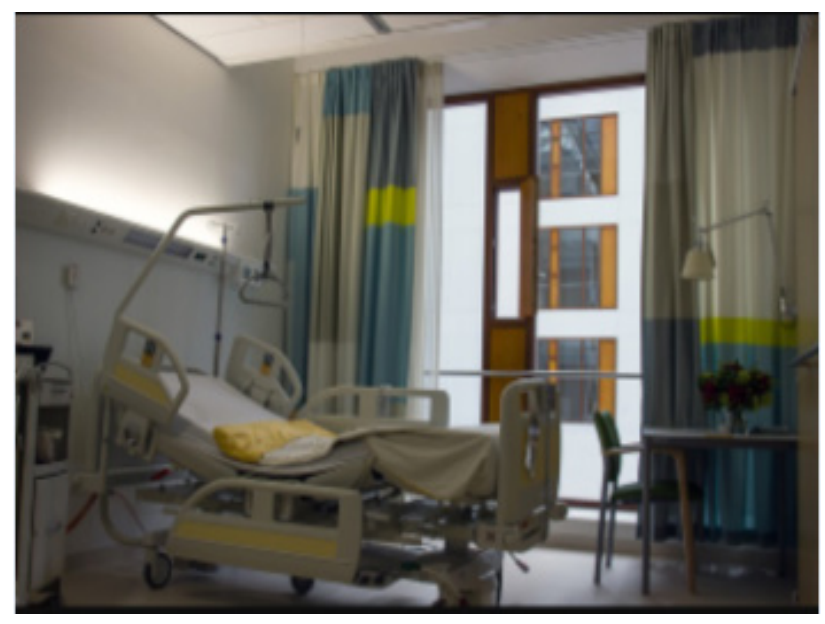

Source: Authors Field Work, 2018

Plate 29. Interior view of a Single Room ward

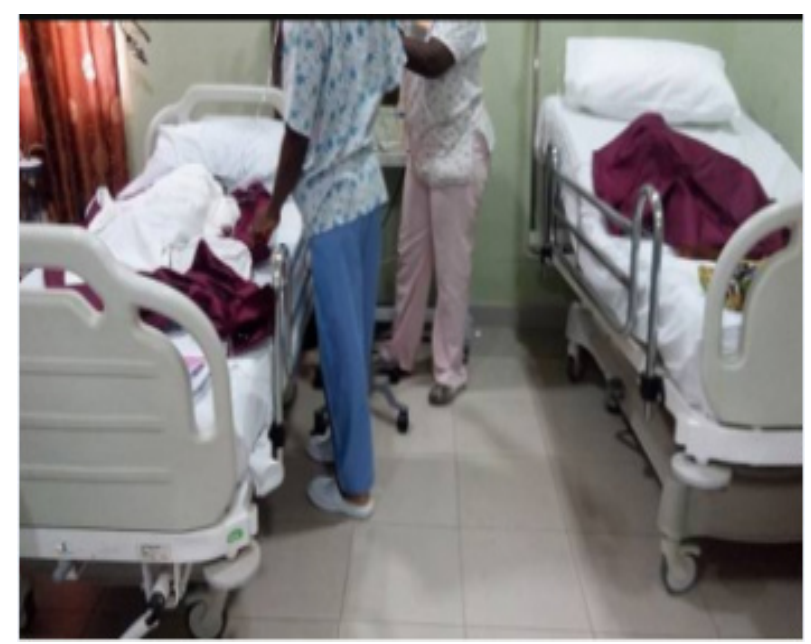

Source: Authors Field Work, 2018

Plate 30. Interior view of Double -Bedded Ward

\subsubsection{Wayfinding within the Physical Facilities}

Finding the way to locate the paediatric department and main entrance to the department are not too difficult but requires adequate and proper labeling. The attached physical facilities relating to restaurant, religion ATM points and banking facilities are very far from the department. However, stairways to the next floor, parking 
lots, toilet, water, sanitary facilities, and different types of wards, clinical facilities spaces, treatment, examination, consulting and counseling rooms were not properly labeled for easy identification and location. Also, Sign post were not clearly placed to locate the out-patient physical facilities such as waiting, reception and record unit, laboratory, diagnostics and pharmacy store.

\subsubsection{Flexibility within the Physical Facilities}

Flexibility and adaptability is an important design characteristic for this study. From appraisal, the flexibility and adaptability of designed spaces in the $\mathrm{UCH}$, Ibadan is very bad. Except the children's clinic located on the first floor of the hospital which is used as the outpatient unit of the pediatric department. The spatial design exhibits inadequate flexibility use of internal space and future expansion. In fact, some of the spaces are not available to perform other activities in offices, working space and department in general. However, some space designed for office use, working, consulting among others spaces cannot be used for another purpose apart from their initial design purposes.

\section{Conclusions and Recommendations}

This study have succeeded in appraising the design characteristics of the physical facilities with special focus on psychological design issues such as wayfinding, proximity, privacy, flexibility\& adaptability of the physical facilities at the selected children hospitals in both the developed and developing nations. It was discovered that design characteristics has a great influence on both the patients and staff. However, this was done with a view to examine how the design characteristics of Emma Children's Hospital in Netherlands have complied with the design characteristics relating to wayfinding, proximity, privacy, flexibility\& adaptability during the design process. The design of Emma Children Hospital was found to have complied with the design characteristics relating to the design issues discussed above, but more could still be done to comply with adequate standard as required by world health organization. The Paediatric Department of University College Hospital, Ibadan had not adequately complied with these design issues. The Paediatric department was used to generalized the design situation in the paediatric hospitals in southwestern, Nigeria.

It is, however, concluded that the Southwestern Nigeria paediatric hospital health providers, managers and designers should learn their lesson by engaging in adequate study of most paediatric hospitals in the developed world and standard required by world health organization WHO to see what is required or criteria of creating or providing healthcare physical facilities for different categories of patients and staff. Finding of the review of literature shows that, appraisal of hospital buildings is usually based on subjective and objective issues and majority of previous studies tended to focus more on the part of hospital design facilities to provide a good planning service for its users which in turn determine individual level of satisfaction.

The literature review identified published studies from little countries in the Africa and Nigeria in particular. This is not good enough; the situation may highlight the need to strengthen capacity for research in this region and help to improve the physical facilities in healthcare environment in the developing nations.

Another problem identified from the Nigerian paediatric Hospitals include initial design considerations of the existing facilities in term of number of patient per ward, space availability, organization, location, accessibility among others. Many of these hospital facilities could no longer meet up with the current healthcare design and services in Nigeria and this has drastically affect the patient well-being or healing process and even reduced the staff performances. Hence, appraisal of the existing healthcare facilities should be carried out to modify through change or redesign, for example, existing physical structures or spaces within the hospital environment may be restructured or improved upon such as additional space provided in waiting areas and patient-care rooms among others. Thus, experts and researchers are needed to develop strategies for renovation and reconstruction of new building and environmental facilities to address the current healthcare growth in Nigeria. The study will provide information on the importance of design quality on overall hospital design quality and performance. It will also contribute to methods of appraising space design quality paediatric hospitals in Nigeria. Finally, future research should aim to develop locally relevant and reliable criteria and standards that would serve as benchmarks to compare performance in relation to patient and staff views and to identify quality gaps. 
Table 1. Showing the summary of design Characteristics Appraisal of the Selected Study Area

\begin{tabular}{|c|c|c|c|c|c|c|c|c|c|c|c|}
\hline \multicolumn{6}{|c|}{$\begin{array}{l}\text { Emma Kinderziekenhuis Pediatric Hospital In Amsterdam, } \\
\text { Netherland }\end{array}$} & \multicolumn{6}{|c|}{$\begin{array}{l}\text { The University College Hospital (UCH), Ibadan, Oyo State, } \\
\text { Nigeria }\end{array}$} \\
\hline & V.Poor & Poor & Fair & Good & $\begin{array}{l}\text { V. } \\
\text { Good } \\
\end{array}$ & & V.Poor & Poor & Fair & Good & V.Good \\
\hline Proximity & & & & & & Proximity & & & & & \\
\hline Privacy & & & & & & Privacy & & & & & \\
\hline Wayfindings & & & & & & Wayfindings & & & & & \\
\hline $\begin{array}{l}\text { Flexibility and } \\
\text { Adaptability }\end{array}$ & & & & & & $\begin{array}{l}\text { Flexibility } \\
\text { and } \\
\text { Adaptability }\end{array}$ & & & & & \\
\hline
\end{tabular}

\section{REFERENCES}

[1] Alalouch, C., Aspinall, P.A and Smith, H., (2016). Design Criteria for Privacy-Sensitive 10.7763/IJET.2016.V8.854 32. Vol. 8, No. 1, February.

[2] Altman, I. (1975), The environment and social behaviour. Monterey, CA: Brooks/Cole.

[3] Alvaro,C., Wilkinson, A.J., Gallant, S.N , Kostovski, D. \& Gardner, P., (2015). Evaluating Intention and Effect: The Impact of Healthcare Facility Design on Patient and Staff Well-Being. Health Environments Research \& Design Journal, Vol. 9(2) 82-104. sagepub.com/journals Permissions. Approach, London: Sage Publication.

[4] Arthur, P.and Passini,R. (1992), Wayfinding: People, Signs, and Architecture. New York: McGraw-Hill.

[5] Barlas, D. et al. (2001). Comparison of the auditory and visual privacy of emergency department treatment areas with curtains versus those with solid walls, Annals of Emergency Medicine, 38(2), 135-139.

[6] Becker, F. D., Sweeney, B., \& Parsons, K. (2007). Ambulatory facility design and patients' perceptions of healthcare quality. Health Environments Research \& Design Journal, 1(4), 35-54.

[7] Berg, A. E. V. d. (2005). "Health impacts of healing environments: a review of evidence for benefits of nature, daylight, fresh air, and quiet in healthcare settings. Groningen: University Hospital Groningen.

[8] Blumberg, R. and Devlin, A. (2006). Design issues in hospitals: The adolescent client. Environment and Behaviour, 38(3), pp. 293-317.

[9] Carpman J., Grant M. and Simmons D. (1986), Design that Cares: Planning Health Facilities for Patients and Visitors. Chicago: American Hospital Publishing.

[10] Dalke, H., J. Little, et al. (2006). "Colour and lighting in hospital design." Optics and Laser Technology 38(4-6): 343-365.

[11] Department of Health and Children (2000) National Children's Strategy: Our Children - Their Lives.
Dublin,Ireland: The Stationery Office.

[12] Devlin, A. S. \& Arneill, A., B. (2003). Health care environments and patient outcomes. Environment and behavior, 35(5), 665-694.

[13] Fischl, G, (2004). A Psychosocial Approach to Architectural Design: A Methodological Study. Division of Engineering Psychology, Department of Human Work Sciences, Luleå University of Technology, Sweden Pp 1-96.

[14] Ghazali, R., \& Abbas, M. Y. (2011). Pediatric Wards: Healing Environment Assessment. Asian Journal of Environment-Behaviour Studies (Aje-Bs), 2(4), Pp. 63-76.

[15] Guenther,R.\&Vittori,G (2008). Sustainable Healthcare architecture New Jersey Wiley \& Sonsilne Beheshti Publications, Tehran.

[16] Hamilton, D. K. (2009). Certifi Cation for Evidence-Based Projects. Healthcare Design, 4, 43-46.

[17] Henriksen, K., Isaacson, S., Sadler, L., \& Zimring, M. C. (2007). The role of the physical environment in crossing the quality chasm. The Joint Commission Journal on Quality and Patient Safety, 33, 68-80.

[18] Huelat, B. (2007), Wayfinding: Design for Understanding. A Position Paper for The Centre for Health Design's Environmental Standards Council.

[19] Hussain, K. \& Babalghith, A.O, (2014). Quality of Hospital Design in Healthcare Industry: History, Benefits And Future Prospect. International Journal of Research in Applied, Natural and Social Sciences. Vol. 2, Issue 5, 61-68.

[20] Jones, W J and Bullard, M (1993). Translating operational change into facility design. Healthcare Forum Journal, 36(1), 67-69.

[21] Khan, N. (2012). Analyzing Patient Flow: Reviewing Literature to Understand the Contribution ofSpace Syntax to Improve Operational Efficiency in Healthcare Settings Department of Architecture, University of Kansas, United States. Proceedings: Eighth International Space Syntax Symposium Edited By M. Greene, J. Reyes and A. Castro. Santiago, Pp 1-11.

[22] Kline, T. J. B, Baylis, B. W., Chatur, F., Morrison, S. A., White, D. E., Flin, R. H., Ghali, W. A, (2007). Patient Satisfaction: Evaluating the Success of Hospital Ward Redesign. Journal for Healthcare Quality Vol. 29, Issue 3, 
Pp 44-49.

[23] Lambert,V., Coad, J, Hicks, P., Glacken, M., (2013). Young children's perspectives of ideal physical design features for hospital-built environments. Journal of Child Health Care; Vol. 18(1) 57-71.

[24] LaVela,S .L , Etingen, Hill, J.N \& Miskevics, S., (2015). Patient Perceptions of the Environment of Care in Which Their Healthcare is Delivered. Health Environments Research\& Design Journal 2016, Vol. 9(3) 31-46.

[25] Lule, G.S, Tugumisirize, J. \& Ndekha, M. (2000) “Quality of care and its effects on utilisation of maternity services at health centre level," East African Medical Journal, vol. 77, no. 5 , pp. 250-255.

[26] Lieburg, M. J. van (2004), De geschiedenis van het Sophia Kinderziekenhuis te Rotterdam, Roterdam: Erasmus publishing.

[27] Marberry, S. (Ed.) (2006). Improving healthcare with better building design. Chicago : Health Administration Press.

[28] Mead, N., \& P. Bower, P. (2002). Patient-centred consultations and outcomes in primary care: a review of the literature," Patient Education and Counselling, vol. 48, no. 1, pp. 51-61.

[29] Miller, C. L., White, R., Whitman, T. L., O'Callaghan, M. F., \& Maxwell, S. E. (1995). The effects of cycled versus non cycled lighting on growth and development in preterm infants. Infant Behavior and Development, 18(1), 87-95.

[30] Newell, P. B. (1998). "A Cross-Cultural Comparison of Privacy Definitions and Functions: ASystem Approach," Journal of Environmental Psychology, Vol. 18, Pp. 357-371, 1998.

[31] Ogaji, D.S., Giles, S., White G.D \& Bower, P., (2015). Systematic review of patients' views on the quality of primary health care in sub-Saharan Africa 3: Pp 1-11

[32] Oladejo, E, Umeh, E, Ogbuefi, J., (2015). An Examination of Impact of Tertiary Healthcare Facility Design on User Needs and Satisfaction in South East Nigeria. Journal of Environment and Earth Science Vol.5, No.5, ISSN 2224-3216.

[33] Offringa, M. (2003), Meten en Wegen. Amsterdam: Amsterdam University Press.

[34] Parke, B., (2007). Physical Design Dimension of an Elder Friendly Hospital: An evidence-based practice review undertaken for the Vancouver Island Health Authority. University of Victoria Centre on Aging. Pp 2-26.

[35] Pinhão, C, S, F (2016). Children's Hospital. The role of architecture in children's recovery and development. Thesis to obtain the Master of Science Degree in architecture. May, 2016. Supervised by Prof. Maria Alexandra de Lacerda Nave Alegre. Tecnico Lisboa.

[36] Pitt, M, Chotipanich, S, Issarasak, S., Mulholland \& Panupattanapong P., (2016). An examination of facility management, customer satisfaction and service relationship in the Bangkok healthcare system. Indoor and Built Environment Vol. 25(3) 442-458

[37] Quan, X., Joseph, A., Keller, A., \& Taylor, E. (2011).
Designing safety-net clinics for innovative care delivery models. Concord, CA: The Center for Health Design.

[38] Reiling, J Ronda G. Hughes, R.G, Murphy, M.R, (2003). The Impact of Facility Design on Patient Safety. Patient Safety \& the Built Environment. Patient Safety and Quality: An Evidence-Based Handbook for Nurses: Vol. 2 Pp 167-188.

[39] Samah, Z.A, Ibrahim,N, Wahab, M.H, (2013). Users' Assessment on Interior Environment of a Hospital Outpatient Unit in Malaysia. Asian Journal of Environment-Behaviour Studies, Vol. 4, Number 11, January/February.

[40] Schaeffer, P.L, Deraiseh, N.M, Daum, L, Huth, M.M, (2012). Pediatric inpatient falls and injuries: A descriptive analysis of risk factors. Journal for Specialists in Pediatric Nursing Vol. 17(1); Pp 1-10.

[41] Shepley, M. M., \& Song, Y. (2014). Design research and the globalization of healthcare environments. Health Environments Research \& Design Journal, 8(1), 158-198.

[42] Solove, D. J. (2006). “A taxonomy of privacy,” University of Pennsylvania Law Review, vol. 154, no. 3, pp. 477

[43] Steinke, C. (2015). Assessing the physical service setting: A look at emergency departments. Health Environment Research and Design Journal, 8, 31-42.

[44] Sundstrom, E. (1980). Work places: The psychology of the physical environment in offices and factories. Cambridge, UK: Cambridge University Press.

[45] Tellier, L. (2009), Urban World History, an economic and geographical perspective, Canada: Presses del l'Université du Québec.

[46] Thompson and Goldin (1975). The Hospital: A social and architectural history. New Haven, CT: Yale University Press.

[47] Teicholz, E. (2001). Facilities Design and Management Handbook. New York. MCGAW-HILL

[48] Todd S, Steele A, Douglas C. and Douglas M. (2002). Investigation and assessment of attitudes to and perceptions of the built environments in NHS trust hospitals. Structural Survey. Vol. 20, Pp. 182-188.

[49] Tompkins, J.A \& Reed, R. Jr. (1996). An applied model for the facilities design problem. International Journal of Production Research: 14:583- 595.

[50] Ulrich, R., \& Zimring, C. (2004). The role of the physical environment in the hospital of the 21st century: A once in a lifetime opportunity. Concord, CA: Robert Wood Johnson Foundation, Center for Health Design.

[51] Ulrich, R., \& Zimring, C. Joseph, A., Quan, X., \& Choudhary, R.(2004). The Role of the Physical Environment in The Hospital of The 21st Century: A Once-In-A-Lifetime Opportunity.

[52] Ulrich, R., (2000). Effects of Healthcare Environmental Design on Medical Outcomes. Design and Health World Congress and Exhibition (WCDH), USA: The International Academy For Design And Health (IADH), 2000.Unit. 
[53] Verdeber S. \& Fine D., (2000). Healthcare Architecture In An Era of Radical Transformation, Yale University Press, New Haven And London.

[54] Zwart, J.V \& Voordt, T.J.M, (2015). Pre-Occupancy Evaluation of Patient Satisfaction in Hospitals. Health Environments Research \& Design Journal; Vol. 9(1) 110-124. 